\title{
PROPENSÃO À MODIFICAÇÃO DE RIOS A PARTIR DA SENSITIVIDADE DE ESTILOS FLUVIAIS EM UMA BACIA HIDROGRÁFICA NO SEMIÁRIDO DA PARAÍBA (BRASIL)
}

\author{
Jeferson Mauricio Rodrigues \\ Doutorando no Programa de Pós-Graduação em Geografia \\ Universidade Federal da Paraíba (PPGG-UFPB), Paraíba, Brasil. \\ Jefersonmrgeo@gmail.com
}

\author{
Jonas Otaviano Praça de Souza
de Pós-Graduação em Geografia \\ Universidade Federal da Paraíba (PPGG-UFPB), Paraíba, Brasil. \\ jonas.souza@academico.ufpb.br \\ Rafael Albuquerque Xavier \\ Professor Adjunto da Universidade Estadual da Paraíba (UEPB), Paraíba, Brasil. \\ xavierra@uol.com.br
}

\begin{abstract}
RESUMO
O conceito de sensitividade se perdeu nos últimos anos entre os trabalhos que tratam sobre a temática de evolução e recuperação de ambientes fluviais semiáridos. Todavia, o conceito e metodologia de sensitividade permite identificar e compreender trechos fluviais que apresentam propensão à mudança. Pesquisas feitas no semiárido australiano pelos pesquisadores Brierley e Friys indicam que a metodologia de sensitividade permite avaliar a propensão à modificação de rios a partir da análise de geoindicadores e seus respectivos subgeoindicadores. O objetivo desta pesquisa foi de entender a propensão à m udança de canais a partir da identificação dos níveis de sensitividade em cada estilo fluvial na bacia hidrográfica do alto curso do rio Piranhas, semiárido paraibano. Foram analisados alguns geoindicadores que permitiram apontar as possíveis alterações no ambiente fluvial de cada estilo que foram: a morfologia do canal, planta do canal e as características de leito. Esses geoindicadores permitem analisar o nível de resistência do ambiente fluvial a partir da análise dos subgeoindicadores, que são elementos que compõem sistema fluvial. Foi possível identificar seis estilos fluviais, conforme suas características de vale, unida des geomórficas e textura. Os estilos confinados apresentaram baixa sensitividade por conta dos controles nas margens e leito rochosos. O EFNCRC foi o estilo que apresentou alta sensitividade, por conta da energia de fluxo moderada e leito e margens móveis. Por fim, foi feita uma análise estatística com base nos dados do índice de sinuosidade aplicado em cada estilo que propiciou maior entendimento acerca das diferentes alterações na forma em planta dos estilos fluviais analisados, buscando quantificar os ajustes fluviais.
\end{abstract}

Palavras-chave: Sensitividade. Estilos Fluviais. Evolução de canais.

\section{PROPENSION TO RIVERS MODIFICATION FROM THE SENSITIVITY OF FLUVIAL STYLES IN A HYDROGRAPHIC BASIN IN THE SEMI-ARID OF PARAÍBA (BRAZIL)}

\begin{abstract}
The concept of fluvial sensitivity has been lost in recent years among works dealing with the theme of evolution and recovery of semi-arid fluvial environments. However, the concept and methodology of sensitivity allow us to identify and understand river stretches prone to change. Researches done in the Australian semiarid by researchers Brierley and Friys indicate that the sensitivity methodology allows assessing the propensity to modify rivers based on the analysis of geoindicators and their respective subgeoindicators. In this perspective, this research's objective was to understand the propensity to change channels based on the identification of the levels of sensitivity in each river-style identified in the hydrographic basin of the upper course of the Piranhas River, a semi-arid region in Paraíba. For this, some geoindicators were analyzed to point out the possible changes in the fluvial environment of each style: the morphology of the channel, the shape of the channel plan, and the bed characteristics. These geoindicators allow to analyze the resistance level of the fluvial environment from the analysis of the subgeoindicators, which are elements that make up the fluvial system. It was possible to identify six river styles according to their valley characteristics, geomorphic units, and texture. The confined river styles were those with low sensitivity due to the controls on the banks and bedrock. The Rocky and Gravel Unconfined Fluvial Style was the one that showed high sensitivity due to the moderate flow energy and bed and moving margins. Finally, a statistical analysis was made based on the data of the sinuosity index applied in each style, which provided a greater understanding of the different changes in the plan shape of the analyzed river styles, seeking to quantify the river's adjustments styles.
\end{abstract}

Keywords: Sensitivity. River styles. Evolution of channels.

Caminhos de Geografia $\quad$ Uberlândia-MG $\quad$ v. 22, n. $82 \quad$ ago./2021 $\quad$ p. 292-313 Página 292




\section{INTRODUÇÃO}

A preocupação com a vitalidade de sistemas fluviais é algo crescente nas últimas décadas no mundo inteiro e forneceu base para a identificação e reabilitação de sistemas fluviais degradados (Friyrs, 2003). Todavia, um conceito que caiu em desuso nos últimos anos é o de sensitividade fluvial, e que deveria estar no centro das análises de rios, pois um viés da geomorfologia fluvial que ainda não foi totalmente explorado é o de evolução da paisagem. De modo geral, a sensitividade fluvial é a propensão à mudança de um canal frente a uma perturbação, ou seja, é relativa à magnitude da força de perturbação relacionada aos diferentes níveis de resistência de um rio (FRYIRS, 2017).

Apesar do reconhecimento de longa data, desde a década de 1920 do conceito de sensitividade na geomorfologia fluvial, ocorreram poucas tentativas de desenvolver uma abordagem sistemática e consistente para analisar a sensitividade de rios (Reid e Brierley, 2015). A sensitividade pode ser entendida como a probabilidade de uma determinada mudança nos controles de um sistema que produza respostas sensíveis, reconhecíveis e persistentes. Desta maneira, a questão da sensitividade abrange dois aspectos: (1) a propensão à mudança; (2) a capacidade do sistema em absorver a mudança (BRUNSDEN, 2001).

A morfologia de um rio se ajusta continuamente através do equilíbrio entre resistência e perturbação numa perspectiva lateral e vertical, desta maneira a morfologia atua como geoindicador de graus de liberdade de um canal fluvial. Assim, o ajuste vertical refere-se à estabilidade do leito de um rio, enquanto 0 ajuste lateral refere-se às margens. Outro conceito importante a ser levado em consideração é o de capacidade de ajuste, que é uma medida de extensão em que um respectivo trecho pode se ajustar, podendo o canal ajustar-se nas dimensões lateral ou vertical (FRIYRS, 2017).

Brierley e Fryirs (2005) utilizam o conceito/metodologia de sensitividade como suporte para compreender a evolução histórica de rios em um ambiente semiárido na Austrália. Fryirs (2017) discute teoricamente o conceito de sensitividade e o propõe como possibilidade para compreender cenários futuros, probabilidade à mudança e evolução geomórfica de rios. No Brasil, Boas e Marçal (2013) analisaram a sensitividade fluvial embasados em uma relação entre a energia (pluviosidade) e resistência do tipo de uso do solo na bacia do rio Macaé - RJ, identificando que a precipitação foi fator decisivo na alteração da dinâmica fluvial entre 1990 e 2010 . Kleina e Santos (2017) definiram a sensitividade fluvial nas principais drenagens do rio Sagrado - PR, e identificou queos maiores ajustes fluviais ocorreram nas áreas de alta sensitividade, especialmente nos ambientes fluviais de baixa declividade aluviais.

A identificação da sensitividade fluvial pode ocorrer a partir de uma classificação de trechos homogêneos que permita compreender as características de caráter e comportamento fluviais (Brierley e Friyrs, 2005). As classificações de canais fluviais podem ser definidas como um ordenamento ou organização de elementos em conjuntos ou grupos de acordo com sua relação e semelhança (ROSGEN, 1994). Na geomorfologia fluvial, as classificações de tipos de rios têm como objetivo reduzir as complexas unidades de estudos em unidades discretas, ou seja, que facilitem a compreensão (FERNANDEZ, 2016) e o ideal é que a classificação esteja dentro de uma perspectiva sistêmica, podendo ser entendida como um complexo de variáveis em interação (VICENTE; PEREZ FILHO, 2003).

Todavia, comumente as classificações de canais fluviais são geradas para canais perenes de ambientes úmidos e só posteriormente aplicadas e/ou adaptadas em canais de regiões semiáridas, onde os funcionamentos dos sistemas hídrico e fluvial são completamente diferentes. É importante salientar que o comportamento fluvial normal de canais semiáridos é quando eles estão secos (SOUZA e ALMEIDA, 2015), onde os rios do semiárido são irregulares e seus fluxos desaparecem durante o período de estiagem, apresentando uma característica de caráter intermitente ou efêmera. Desta maneira, o canal intermitente só apresenta fluxo durante o período chuvoso e os canais efêmeros fornecem escoamento superficial de curta duração que varia de horas a poucos dias durante ou logo após o evento de chuva, ocasionando uma descontinuidade (SUTFIN, 2014).

Uma proposta teórico-metodológica aberta e que não necessita de adaptações na sua aplicabilidade em diferentes ambientes morfoclimáticos é a de Estilos Fluviais (River Styles) proposta por Brierley e Friyrs (2000). A estrutura de estilos fluviais permite avaliar o potencial de modificação de qualquer rio, ao ser aplicada de maneira qualiquantitativa seguindo uma sequência de estágios avaliativos que partem da escala de bacia hidrog ráfica para canal, focando principalmente em dados morfológicos do ambiente fluvial (BRIERLEY e FRIYRS, 2005). Estilos de rio nada mais são que trechos representativos de processos e formas semelhantes/homogêneos. Nesse sentido, são definidos a partir da análise da configuração de vale, identificação de unidades geomórficas e análise da textura de material de leito. Nessa perspectiva, cada estilo fluvial apresenta um determinado nível de 
sensitividade fluvial, ou seja, cada estilo apresenta uma capacidade diferente de se ajustar a eventos de perturbação (FRIYS, 2003).

Atualmente, a estrutura de estilos fluviais vem sendo gradativamente aplicada em bacias hidrográficas no semiárido brasileiro, fornecendo amplo entendimento dos processos e formas de ambientes fluviais no perímetro seco brasileiro (SOUZA, 2012; SOUZA; BARROS e CORRÊA, 2016; MAIA e SOUZA, 2016; RODRIGUES e SOUZA, 2016; RODRIGUES e SOUZA, 2020a). Nessa perspectiva, essa proposta teórico-metodológica vem fornecendo base teórica e dados para uma região que possui limitações de dados sobre processos e formas fluviais.

O objetivo desta pesquisa é avaliar a propensão à mudança de canais fluviais a partir da definição de sensitividade fluvial em diferentes estilos fluviais na bacia hidrográfica do alto curso do rio Piranhas, semiárido paraibano. A realização desse objetivo permitirá compreender como canais fluviais podem evoluir no semiárido brasileiro.

\section{Caracterização da área de estudo}

A bacia do alto curso do rio Piranhas situada no sertão do Estado da Paraíba é uma típica bacia hidrográfica de ambiente semiárido. O motivo pelo qual foi escolhida esta área para estudo é que ela mantém características de vazão naturais em praticamente toda a extensão do canal (RODRIGUES, 2020), por não sofrer influência da Barragem Coremas - Mãe D'água (localizada no Rio Piancó Afluente do rio Piranhas), que pereniza artificialmente o Médio e Baixo Curso do Rio Piranhas após a confluência com o rio Piancó e altera suas condições/características naturais de vazão (intermitente). Essa bacia possui rios intermitentes e efêmeros em seu perímetro, além de ser um futuro caminho natural das águas do rio São Francisco, que terá como ligação a cabeceira do rio Piranhas localizada no município de São José de Piranhas, no momento em que o Eixo Norte da transposição estiver concluído (DOMINGUES, 2015). Desta maneira, é importante que haja entendimento geral do comportamento do sistema fluvial do alto curso do rio Piranhas, que será impactado por uma transposição que o perenizará artificialmente.

A área da bacia do Alto Curso do Rio Piranhas, inserida no Sertão paraibano, ocupa uma área de 6010 km², abrangendo 35 Municípios que dentre os principais estão: Cajazeiras, Souza e Pombal, e o canal principal possui 174,22 km de extensão (Figura 1).

Figura 1 - Mapa de localização da bacia do alto curso do rio Piranhas.

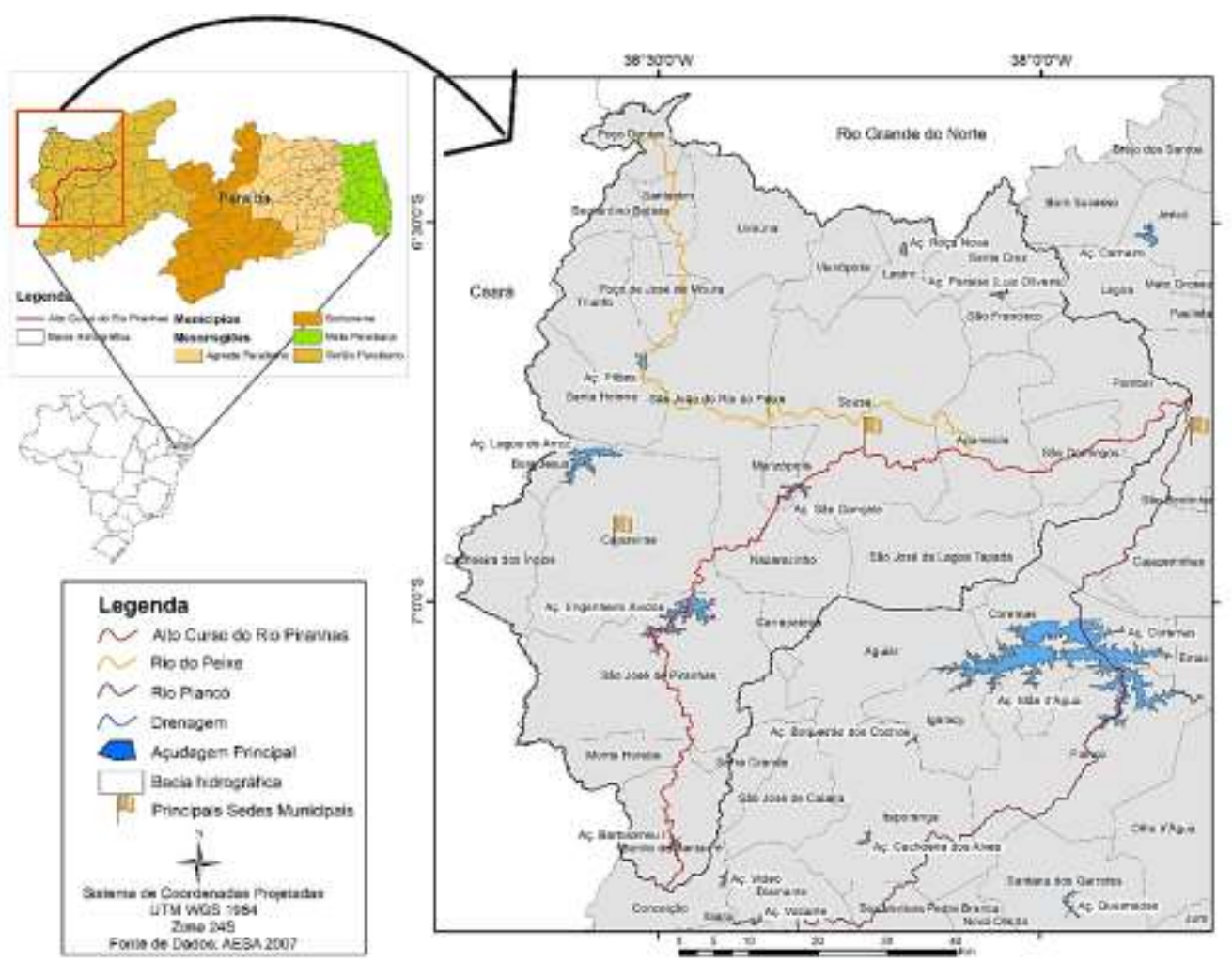

Fonte - RODRIGUES (2020). 
A área da bacia do alto curso do rio Piranhas possui características físicas semelhantes a maioria das áreas do semiárido nordestino. As áreas de altitude intermediárias estão em torno de 300 a $500 \mathrm{~m}$ e apresentam topografia que varia majoritariamente de plano a suave ondulado, onde tais compartimentos deprimidos oriundos de denudação e circundesnundação em torno do planalto da Borborema faz com que essas áreas deprimidas de relevo suave e baixo constituam parte das principais áreas semiáridas do interior do Nordeste brasileiro (MAIA, et al., 2010) e ocorrem principalmente sobre as litologias cristalinas pertencentes à subprovíncia estrutural Rio Grande do Norte, esta última sendo parte da Província Estrutural Borborema (Figura 2).

A bacia está inserida sobre a Depressão Sertaneja que é organizada em torno do Planalto da Borborema, e é resultado de morfologia herdada de processos morfoestruturais, onde nessas zonas aplainadas os processos denudacionais superam os agradacionais, formando vastas superfícies erosivas, e consequentemente, pedimentos entre o sopé das encostas e os ambientes fluviais, onde a coalescência desses pedimentos formam os pediplanos - processos frequentes da chamada Depressão Sertaneja (MAIA, et al, 2010).

De modo geral, as áreas mais elevadas acima de $600 \mathrm{~m}$ de altitude possuem substrato de rochas intrusivas plutônicas paleoproterozóicas e de topo suave ondulado. As áreas intermediárias, com altitudes variando de 300 a $600 \mathrm{~m}$ possuem substratos compostos por complexos metamórficos meso-neoproterozóicos e com amplas áreas íngremes, correspondentes às serras e inselbergs que ocorrem na bacia. As áreas abaixo de $300 \mathrm{~m}$ são constituídas por um substrato sedimentar relacionado a processos de subsidência a partir de reativações das zonas de cisalhamento durante o ciclo brasiliano, onde a principal fase do sistema de rifteamento ocorreu durante o NeocomianoBarremiano, com desenvolvimento dos Rifts Valleys e extenso fraturamento da crosta superior, gerando a única bacia sedimentar intracratônica existente no Estado da Paraíba (NOGUEIRA; OLIVEIRA; CASTRO, 2004), com topografia aplainada e amplas áreas aluviais.

Figura 2 - Altitude e declividade segundo classes da Embrapa no alto curso do rio Piranhas.

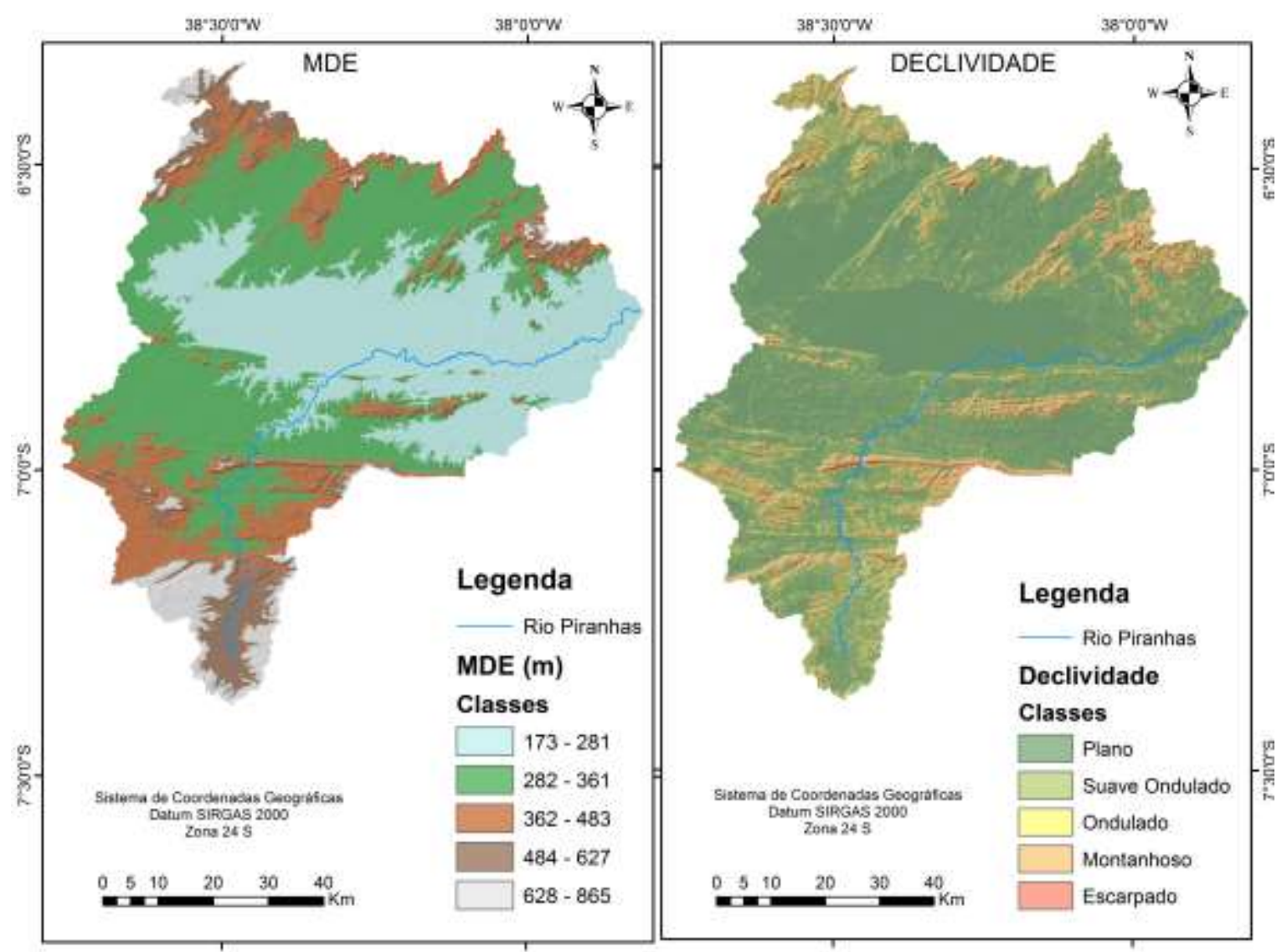

Fonte - Autoral (2020). 
O clima da bacia é típico do semiárido brasileiro, ocorrendo chuvas concentradas entre os meses de fevereiro e abril, os quais correspondem à quadra chuvosa da bacia (Figura 3), sendo gerados por sistemas climáticos como a Zona de Convergência intertropical (ZCIT) que ocorre principalmente durante o verão após o aquecimento do Atlântico Sul que favorece a retração do Anticiclone Semifixo do Atlântico Sul e é responsável por uma grande porção do volume de chuva que ocorre na região (RODRIGUES, 2020b) e também, decorrentes dos Vórtices Ciclônicos de Altos Níveis (VCAN's), sendo estes últimos circulações ciclônicas fechadas, onde o centro é mais frio que seu entorno, causando a subsidência do ar e inibindo a formação de nuvens na sua parte central, com periferias quentes e úmidas, gerando a ascensão/condensação do ar e consequentemente a precipitação (VAREJÃO-SILVA, 2006), e transformam energia potencial em cinética pelo movimento descendente no centro frio e ascendente na periferia (KOUSKY; GAN, 1981), o que determina a qualidade da chuva na região Nordeste do Brasil.

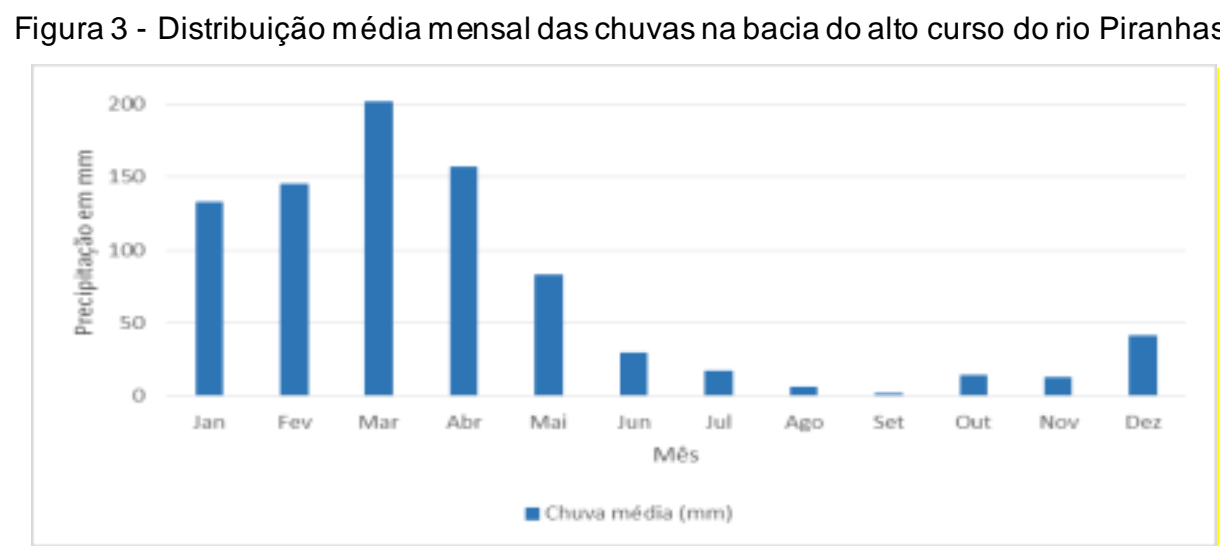

Fonte - Rodrigues (2020b).

Além de distribuição irregular temporalmente, as chuvas também são mal distribuídas espacialmente, onde os setores com altitude entre 300 e 600 m recebem as maiores taxas de precipitação da bacia (RODRIGUES, 2020b).

\section{METODOLOGIA}

De acordo com a proposta teórico metodológica de Brierley e Fryirs (2005), são necessárias alg umas etapas para alcançar a definição de diferentes níveis de sensitividade fluvial para estilos fluviais em uma bacia hidrográfica. Nessa perspectiva, o roteiro desta pesquisa possui 5 etapas de análise, conforme observado no diagrama na Figura 4.

De acordo com a Figura 4, a primeira etapa refere-se à identificação e mapeamento dos estilos fluviais. Para definir e mapear estilos fluviais em uma bacia hidrográfica é necessário avaliar 3 parâmetros de canal: configuração de vale; unidades geomórficas e textura de material de leito (BRIERLEY e FRYIRS, 2005).

A configuração de vale é o procedimento inicial para identificar um estilo de rio, sendo definida pelo grau de confinamento lateral dos trechos fluviais. Este confinamento é expresso pela presença/ausência de planícies de inundação nos trechos (Brierley e Fryirs, 2005). Desta maneira, os canais podem ser confinados (com presença de planície de inundação abaixo de 10\%), parcialmente confinados (com presença de planície de inundação entre 10 e 90\%) e não confinados (com presença de planície de inundação acima de $90 \%$ ). A determinação da configuração de vale é determinada em 2 momentos, o primeiro refere-se à identificação das planícies de inundação nos trechos fluviais a partir de imagens do Google Earth, e, após a definição inicial dessas unidades geomórficas, foram feitos campos para confirmar esses dados em pontos da bacia.

As unidades geomórficas e forma em planta são parâmetros fundamentais para interpretar a característica e o comportamento dos trechos analisados. Os critérios utilizados para identificar as unidades geomórficas são: número de canais, sinuosidade, barras e ilhas. É importante salientar que esta etapa foi feita tanto em gabinete, como também, em campo, considerando a necessidade de confirmação dos dados de gabinete. Em gabinete, esses critérios de análise de unidades geomórficas

$\begin{array}{lllll}\text { Caminhos de Geografia } & \text { Uberlândia-MG } & \text { v. 22, n. } 82 & \text { ago./2021 } & \text { p. 292-313 Página } 296\end{array}$


foram identificados a partir de imagens recentes do Google Earth (2010 a 2019) para a área analisada.

A textura de material de leito é outro procedimento de análise dos estilos, e é determinada através da base do tamanho do grão de material sedimentar presente no leito dos trechos fluviais. Inicialmente foi necessário em campo fazer a coleta de sedimentos no leito dos diferentes estilos fluviais e posteriormente, em laboratório, foi aplicada a metodologia de granulometria por peneiramento para determinar frações de sedimentos grosseiros e pipetagem para sedimentos finos (GALE e HOARE, 1991, apud SILVA e SOUZA, 2017). Para isso foram pesadas $100 \mathrm{~g}$ de cada amostra (totalizando em 11 amostras) e colocadas cada uma em 1 becker de vidro de $500 \mathrm{ml}$ com água e $20 \mathrm{~g}$ de dispersante (hexametafosfato de sódio). As amostras foram agitadas durante 20 minutos contínuos para descompactar as frações dos grãos e, posteriormente ficaram de molho por 24 horas para decantação. Posteriormente, as amostras foram lavadas e colocadas na estufa por um período de 10 horas sob uma temperatura de $70^{\circ} \mathrm{C}$. Por fim, foram submetidas ao agitador eletromagnético de peneiras redondas rotap para determinação da granulometria. Desta maneira, são utilizadas 5 classes: Leito rochoso; Rocha (>256 mm); Cascalho (2 - $256 \mathrm{~mm})$; Areia $(0,0625-2 \mathrm{~mm})$; Silte e Argila $(<0,0625 \mathrm{~mm})$.

Figura 4 - Etapas para definir e validar os níveis de sensitividade de estilos fluviais.

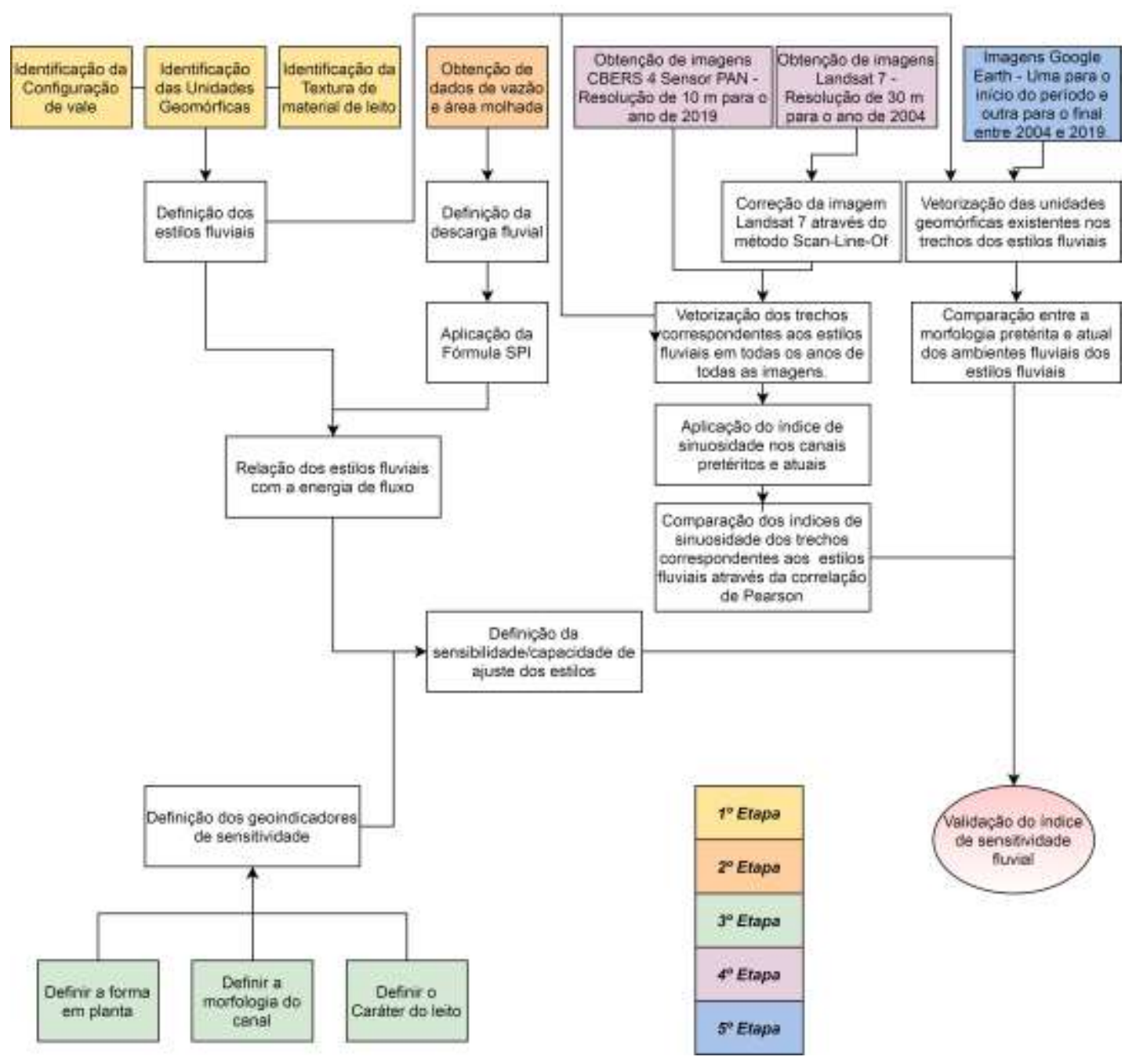

Fonte - Autoral (2020).

Após a definição da configuração de vale, textura de material de leito e identificação das unidades geomórficas foi possível definir os estilos fluviais da bacia, que foram distribuídos em uma matriz de informações gerais estilos fluviais, onde foram evidenciadas as informações obtidas de cada estilos, sua distribuição em porcentagem na bacia e fotografias que representam visualmente a morfologia de cada ambiente fluvial.

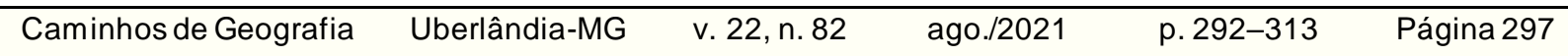


Para segunda etapa desta pesquisa, foi necessário analisar a energia do fluxo que oco rre nos estilos identificados para entender o condicionamento/comportamento do sistema fluvial na bacia hidrográfica do alto curso do rio Piranhas e suas respectivas zonas processuais. Para tal, foi aplicado o SPI (Stream Power Index) que é um modelo matemático que permite inferir a energia de fluxo a partir de dados de descarga fluvial. Danielson (2013) afirma que o SPI é utilizado para mensurar o poder de erosão da água em um terreno, onde áreas que possuem índices altos de Strem Power possuem ótimas condições para gerar erosão. Segundo Rosa (2019), o SPI pode ser obtido através da seguinte equação:

$\Omega=$ p.g.Q.S

Onde a $\Omega$ é o Stream Power Índex; $p$ é a densidade da água; g é a força da gravidade; $Q$ é a descarga; e $S$ é a declividade em graus do terreno.

O valor da descarga é obtido através da multiplicação entre velocidade do fluxo e área molhada, expressa da seguinte maneira:

$Q=A * U$

Onde $A=$ Área molhada no vale fluvial; $U=$ Velocidade do fluxo.

Os dados de descarga foram obtidos para as estações fluviométricas São Domingos de Pombal (código 37297000), Aparecida (código 37290000) e Várzea Grande (código 37220000) na plataforma do Hidroweb da Ana (Agência Nacional das Águas). Através de uma tabela foi feita uma análise entre os estilos fluviais identificados e determinados seus parâmetros de controle que operam em cada estilo. Os parâmetros avaliados foram: processo de zona, conf inamento lateral, textura de material de leito, unidades geomórficas e energia de fluxo.

A terceira etapa consiste em definir os geoindicadores de sensitividade. Para esse estudo os geoindicadores utilizados foram: atributos do canal, forma em planta e material de leito destrinchados em respectivos sub-geoindicadores. Dessa forma, foi gerada uma tabela com informações de sensitividade de estilos organizados por confinamento de vale e seus geoindicadores principais, onde esta etapa forneceu um guia inicial para os estilos de rios com maior probabilidade à mudança (Quadro 1).

Quadro 1 - Procedimentos para cada geoindicador.

\begin{tabular}{|c|c|c|}
\hline Geoindicador & Definição & $\begin{array}{c}\text { Exemplos de técnicas e ferramentas usadas para } \\
\text { analisar cada geoindicador }\end{array}$ \\
\hline \multicolumn{3}{|c|}{ MORFOLOGIA DE CANAL } \\
\hline Tamanho & Largura e profundidade do canal & $\begin{array}{l}\text { Razão de profundidade e largura em relação à área } \\
\text { de captação que drena }\end{array}$ \\
\hline $\begin{array}{lr}\text { Forma } & e \\
\text { morfologia da } \\
\text { margem }\end{array}$ & $\begin{array}{l}\text { A forma da seção transversal do } \\
\text { canal }\end{array}$ & $\begin{array}{l}\text { É a identificação se é regular, irregular, composta, } \\
\text { simétrica ou assimétrica. Também relaciona a textura } \\
\text { da margem com base em tamanho dos grãos. }\end{array}$ \\
\hline \multicolumn{3}{|c|}{ FORMA EM PLANTA DO CANAL } \\
\hline $\begin{array}{l}\text { Número de } \\
\text { canais }\end{array}$ & Quantidade de canais no leito fluvial & $\begin{array}{l}\text { Identificar se o canal é único, múltiplo, contínuo ou } \\
\text { descontínuo }\end{array}$ \\
\hline $\begin{array}{l}\text { Sinuosidade de } \\
\text { canais }\end{array}$ & $\begin{array}{l}\text { O grau de curvatura do canal ao } \\
\text { longo do seu vale }\end{array}$ & $\begin{array}{l}\text { A razão entre a extensão do canal e a extensão do } \\
\text { seu vale encaixante. }\end{array}$ \\
\hline $\begin{array}{l}\text { Estabilidade } \\
\text { lateral }\end{array}$ & $\begin{array}{l}\text { O grau em que o canal pode se } \\
\text { mover entre os limites do seu vale }\end{array}$ & $\begin{array}{l}\text { Identificação de expansão de canal, erosão de } \\
\text { margem e migração }\end{array}$ \\
\hline $\begin{array}{l}\text { Unidades } \\
\text { geomórficas }\end{array}$ & $\begin{array}{l}\text { Cada unidade geomórfica possui } \\
\text { uma distinção entre forma-processo }\end{array}$ & $\begin{array}{l}\text { Análise de forma e sedimentologia para interpretar os } \\
\text { processos responsáveis de formação das unidades } \\
\text { geomórficas }\end{array}$ \\
\hline \multicolumn{3}{|c|}{ CARATERISTICA DO LEITO } \\
\hline Textura do leito & $\begin{array}{l}\text { Tamanho e distribuição de material } \\
\text { transportado e depositado no leito }\end{array}$ & $\begin{array}{l}\text { Estimativas visuais da porcentagem do leito que } \\
\text { compreende diferentes frações de tamanho de grão }\end{array}$ \\
\hline $\begin{array}{l}\text { Estabilidade do } \\
\text { leito }\end{array}$ & $\begin{array}{l}\text { Capacidade do leito de se ajustar } \\
\text { verticalmente }\end{array}$ & Interpretação de ação vertical de incisão no leito \\
\hline
\end{tabular}

Fonte - Adaptado de Brierley e Friyrs, 2005.

p. 292-313 Página 298


A definição dos geoindicadores é a base para relacionar os dados dos estilos identificados com uma estrutura qualitativa pré-determinada por Brierley e Friyrs (2005) que relaciona o potencial de sensitividade (baixo, moderado e alto) de acordo com as características dos tipos de vale identificados nos estilos fluviais. Neste momento da pesquisa será avaliado o potencial do rio em se ajustar dentro de seus vales. Desta maneira a análise deste procedimento parte da identificação de qual tipo de mudança ocorreu no ambiente fluvial, se erosiva ou deposicional ou de estilo de rio conforme Souza (2015) focando nos geoindicadores analisados que apresentaram mudança (Figura 5).

Foi necessário comprovar visualmente os estilos de acordo com seus níveis de sensitividade fluvial, que são os estilos com alta sensitividade (Estilo Fluvial Não Confinado Rochoso e Cascalhento EFNCRC); sensitividade moderada (Estilo Fluvial Parcialmente Confinado Cascalhento - EFPCC, Estilo Fluvial Não Confinado Arenoso - EFNCA, Estilo Fluvial Parcialmente Confinado Arenoso EFPCA); e baixa sensitividade (Estilo Fluvial Confinado Rochoso - EFCR, Estilo Fluvial Confinado Cascalhento e Arenoso - EFCCA). Assim, a validação dos diferentes níveis de sensitividade ocorreu a partir da obtenção de imagens de satélite que permitissem identificar a forma em planta dos diferentes estilos fluviais. Portanto, foi necessário utilizar diferentes satélites como base, pois a resolução espacial mais detalhada e de acesso livre varia. Assim, optou-se pelas imagens do Landsat 7, considerando que atua desde 1999 sob uma resolução de $30 \mathrm{~m}$ e foram obtidas através da plataforma da USGS - Earth Explorer. A escolha das imagens do CBERS 4 para análise recente é justificada pelo fato de possuir uma resolução espacial de $10 \mathrm{~m}$, permitindo identificar com maior propriedade a forma em planta recente do canal. As imagens do CBERS 4 foram obtidas através da Divisão de Geração de Imagens do INPE (Instituto Nacional de Pesquisas Espaciais), que possui um catálogo de Imagens de diversos satélites que orbitam a Terra. E as imagens do Google Earth foram fundamentais para definição das modificações no ambiente fluvial. De maneira geral, o tempo de análise dos estilos fluviais foi a partir da série temporal de disponibilidade de imagens do Google Earth para a área da bacia hidrog ráfica do alto curso do rio Piranhas, que varia de 2004 a 2019.

Portanto, foi utilizada uma imagem do Landsat 7 datada de 25/10/2004(órbita e ponto 216/65) e uma imagem do CBERS 4 datada de 17/10/2019 (órbita e ponto 150/108). Contudo, foi necessário fazer a correção da imagem do satélite Landsat 7 , pois passou a apresentar falhas (gaps) nas imagens geradas após maio de 2003, requerendo preenchimento. Para isso, foi necessário seguir a recomendação de correção da USGS a partir do método Scan-Line-Of, ou seja, usar uma imagem SLC Off (mais recente e com falhas datada de 25/10/2004) e outra imagem SLC On que antecede o mês de maio de 2003 (sem falhas datada de 05/10/2001). Logo, foi possível fazer o gape fill com duas cenas diferentes no programa ENVI através da ferramenta Landsat gapfill que permite sobrepor as duas cenas e preencher as falhas.

É importante salientar que após a obtenção dos dados de satélite (Landsat 7, CBERS 4 e Google Earth), a forma em planta dos estilos fluviais foi vetorizada manualmente através da criação de um shape de linha no ArcGis 10.5, permitindo contornar a forma em planta dos estilos tanto para os anos de 2004 e 2019, possibilitando assim aplicar o índice de sinuosidade nos estilos fluviais de acordo com o nível de sensitividade de cada estilo, tendo em vista que a forma em planta é um dos principais geoindicadores de sensitividade fluvial (Quadro 1). Essa aplicação do índice de sinuosidade permite identificar quais estilos fluviais apresentaram maior migração lateral entre os estilos que apresentam maior nível de sensitividade. O índice de sinuosidade é calculado a partir da razão entre a extensão do canal e a extensão do vale. Um índice de sinuosidade $>1,3$ indica um alcance meandrante; o de 1,0 indica um alcance retilíneo; enquanto os alcances sinuosos são aqueles que apresentam índices entre 1,05 e 1,3 (LANGAT, et al. 2020). 
Figura 5 - Proposição de capacidade de ajuste e de sensitividade de acordo com o confinamento de vale.

\begin{tabular}{|c|c|c|c|c|}
\hline $\begin{array}{c}\text { Configuraçāo de } \\
\text { vale }\end{array}$ & Caracteristica do leito & Morfologia do canal & Forma em planta do canal & $\begin{array}{c}\text { Capacidade } \\
\text { natural de ajusie e } \\
\text { sensitividade flovial }\end{array}$ \\
\hline Confinado & $\begin{array}{l}\text { Frequentemente restringido } \\
\text { por leito rochoso, podendo } \\
\text { restringir os ajustes verticais }\end{array}$ & $\begin{array}{l}\text { Tamanho e largura controlados } \\
\text { pela litologia confinante. A } \\
\text { erosäo da margem e } \\
\text { insignificante. }\end{array}$ & $\begin{array}{c}\text { Nào há potencial para } \\
\text { ajuste do numero de canais, } \\
\text { sinuosidade ou estabilidade } \\
\text { lateral. Unidades } \\
\text { geomóticas sảo formas } \\
\text { amplamente impostas. }\end{array}$ & $\begin{array}{c}\text { Baixa. } \\
\text { Canal resiliente. }\end{array}$ \\
\hline $\begin{array}{l}\text { Parcialmente } \\
\text { Confinado }\end{array}$ & $\begin{array}{c}\text { Podem ser contituidos por } \\
\text { diversas texturas de leito. O5 } \\
\text { ajustes de leito sio dependentes } \\
\text { da disponibilidade de materal de } \\
\text { leito e da história da carga } \\
\text { tramsportada. }\end{array}$ & $\begin{array}{l}\text { Tamanho e largura do canal saio } \\
\text { ajustades onde ocorre planicies } \\
\text { de inundaçâo. Assim. } \\
\text { ocorrem ajustes localizados } \\
\text { onde as unidades geomórficas } \\
\text { permitem. }\end{array}$ & $\begin{array}{l}\text { Potencial locul para ajustes } \\
\text { nas curvas do canal, mas a } \\
\text { largura é controlada por } \\
\text { rocha. Planicie de inundaçio } \\
\text { pode ser propensit a ser } \\
\text { modificada ou reformada. }\end{array}$ & $\begin{array}{l}\text { Localizada } \\
\text { e } \\
\text { moderadamente } \\
\text { resiliente. }\end{array}$ \\
\hline $\begin{array}{c}\text { Não confinado com } \\
\text { alta energia e canais } \\
\text { continuos }\end{array}$ & $\begin{array}{l}\text { Podem ser constituidos por } \\
\text { rocha ou por sedimentos } \\
\text { grossos que controlim o leito. } \\
\text { Assim, ocorrem alustes locais. } \\
\text { de forma dramática através de } \\
\text { eventos de alta magnitude. }\end{array}$ & $\begin{array}{l}\text { Tamanho e largura do canal } \\
\text { podem ser ajustados } \\
\text { lateralmente e verticalmente } \\
\text { dependendo das condiçóes de } \\
\text { textura. Há potencial moderado } \\
\text { de erosào da margem. }\end{array}$ & $\begin{array}{l}\text { Potencial signifieutivo para } \\
\text { ajtste do nimero, } \\
\text { sinuosidade e estabilidade } \\
\text { lateral do cantil. Ocorrem } \\
\text { mudanças mas planicies de } \\
\text { imundação. }\end{array}$ & $\begin{array}{l}\text { Moderada } \\
\text { e com } \\
\text { sensibilidade } \\
\text { significativa. }\end{array}$ \\
\hline $\begin{array}{l}\text { Não confinado com } \\
\text { energía média e } \\
\text { canais continuos }\end{array}$ & $\begin{array}{c}\text { O leito pode apresentar } \\
\text { diversas texhiras sendo movel } \\
\text { e sujeito a mudanças verticaí, } \\
\text { caso a lextura scja maleável }\end{array}$ & $\begin{array}{c}\text { Timanho e Jisgura do cumal podem } \\
\text { ser austudos lateralmente e } \\
\text { verticalmente Dependendo diss } \\
\text { condiçóes de textura Ha potencial } \\
\text { significativo para erosio das } \\
\text { margens. }\end{array}$ & $\begin{array}{l}\text { Potencial significalivo para } \\
\text { ajuste do numteno. } \\
\text { sunuosidade e estabilidade } \\
\text { lateral do canat, Oeorrem } \\
\text { mudancas nas planicjes de } \\
\text { inundaçio. }\end{array}$ & Alta e \\
\hline $\begin{array}{l}\text { Não confinado com } \\
\text { baixa energia * } \\
\text { canals continuos }\end{array}$ & $\begin{array}{l}\text { Podem ser constituidos por } \\
\text { texturas finas (Areia, silte e } \\
\text { argila) e nảo apresentam } \\
\text { potencial para evoluçào } \\
\text { vertical. }\end{array}$ & $\begin{array}{l}\text { A capacidade para tamanho, } \\
\text { largura e ajustes laterais e } \\
\text { verticatis e constrangida } \\
\text { por margens coesas ao longo do } \\
\text { sistema de transporte suspenso. }\end{array}$ & $\begin{array}{l}\text { Potencial moderado purı } \\
\text { ajuste no nüumero. } \\
\text { sinuosidade e estabilidiade } \\
\text { lateral. Planicies de } \\
\text { inundaçio sio de grî́os finos } \\
\text { depositados por acresçîio } \\
\text { vertical }\end{array}$ & $\begin{array}{c}\text { Localizada } \\
\text { e } \\
\text { moderadamente } \\
\text { resiliente. }\end{array}$ \\
\hline $\begin{array}{c}\text { Não confinado com } \\
\text { baixa energia e } \\
\text { canais continuos de } \\
\text { embasamento } \\
\text { rochoso }\end{array}$ & $\begin{array}{c}\text { Podem ser constituidos por } \\
\text { leito rochoso c apresentar } \\
\text { variabilidade } \\
\text { limitada por materiais recentes } \\
\text { que se ajustam sobre o leito do } \\
\text { canal. }\end{array}$ & $\begin{array}{l}\text { Condiçâo de leito imposta } \\
\text { Potencial para erosĩo de margem e } \\
\text { ajuste da geometria do canal sâo } \\
\text { dependentes da composiçâo do } \\
\text { canal e da planicie de inundaçio. }\end{array}$ & $\begin{array}{l}\text { Altamente variável } \\
\text { dependendo do tipo de } \\
\text { forma em planta. Tem } \\
\text { eapacidade linitada para } \\
\text { ajustar as unidades } \\
\text { geomórficas. }\end{array}$ & $\begin{array}{c}\text { Localizada } \\
\mathrm{e} \\
\text { moderadamente } \\
\text { resiliente. }\end{array}$ \\
\hline $\begin{array}{c}\text { Nảo confinado com } \\
\text { baixa energia e } \\
\text { canais } \\
\text { descontinuos } \\
\end{array}$ & $\begin{array}{c}\text { Textura do vale dependente do } \\
\text { supprimento de sedimentos. Pode } \\
\text { apresentar potencial de } \\
\text { sedimentiçî̀ em árens de } \\
\text { pântanos e áreas de acumulaçî̉o. }\end{array}$ & $\begin{array}{c}\text { A capacidade para mudança no } \\
\text { tamanho e largura é limitada pela } \\
\text { baixa energia. }\end{array}$ & $\begin{array}{l}\text { Estrutura geomórfica } \\
\text { relativamente simples, } \\
\text { com pequeno potencial } \\
\text { para ajuste. }\end{array}$ & \begin{tabular}{|c|} 
Limitada, \\
moderadamente \\
resiliente, mas \\
muito sensivel à \\
incisảo.
\end{tabular} \\
\hline
\end{tabular}

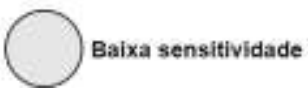

Fonte - Adaptado de Brierley e Friyrs (2005).

Para analisar os dados quantitativos gerados a partir da aplicação do índice de sinuosidade em trechos dos estilos fluviais identificados na bacia, optou-se por trabalhar esses dados em boxplots tanto para o ano de 2004, como também, para o ano de 2009, permitindo uma análise comparativa desses dados.

$\begin{array}{lllll}\text { Caminhos de Geografia } & \text { Uberlândia-MG } & \text { v. 22, n. } 82 & \text { ago./2021 } & \text { p. 292-313 Página } 300\end{array}$




\section{RESULTADOS E DISCUSSÕES}

Inicialmente, a definição de estilos fluviais é realizada a partir de levantamentos de gabinete, no que tange à identificação de confinamento de vale, forma em planta e unidades geomórficas. Posteriormente, o trabalho de campo é realizado para coleta de dados de textura e confirmação de dados de gabinete que servem de base para definir a característica e comportamento do rio, objetivando a busca dos limites de cada estilo (BRIERLEY e FRYIRS, 2005). Assim, foi gerado o mapa de estilos fluviais da bacia hidrográfica do Alto Curso do Rio Piranhas (Figura 6). Observa-se na Figura 6 que o rio Piranhas é diversificado, ou seja, apresenta 6 diferentes estilos fluviais em sua extensão. Inicialmente, esses etilos fluviais estão diretamente relacionados com a variação topográfica e geológica, onde as áreas altas e planas correspondentes às zonas de cabeceira da bacia sofrem influência direta do substrato cristalino composto por rochas ígneas e metamórficas. As áreas mais rebaixadas próximo à foz estão relacionadas com geologia sedimentar. A questão do confinamento das margens indica que os canais confinados estão restritos às áreas de maiores declividades e geologia cristalina, enquanto que os estilos parcialmente confinados e não confinados estão situados sobre áreas predominantemente planas e de geologia que varia de cristalina a sedimentar.

Figura 6 - Estilos Fluviais do Alto Curso do Rio Piranhas.

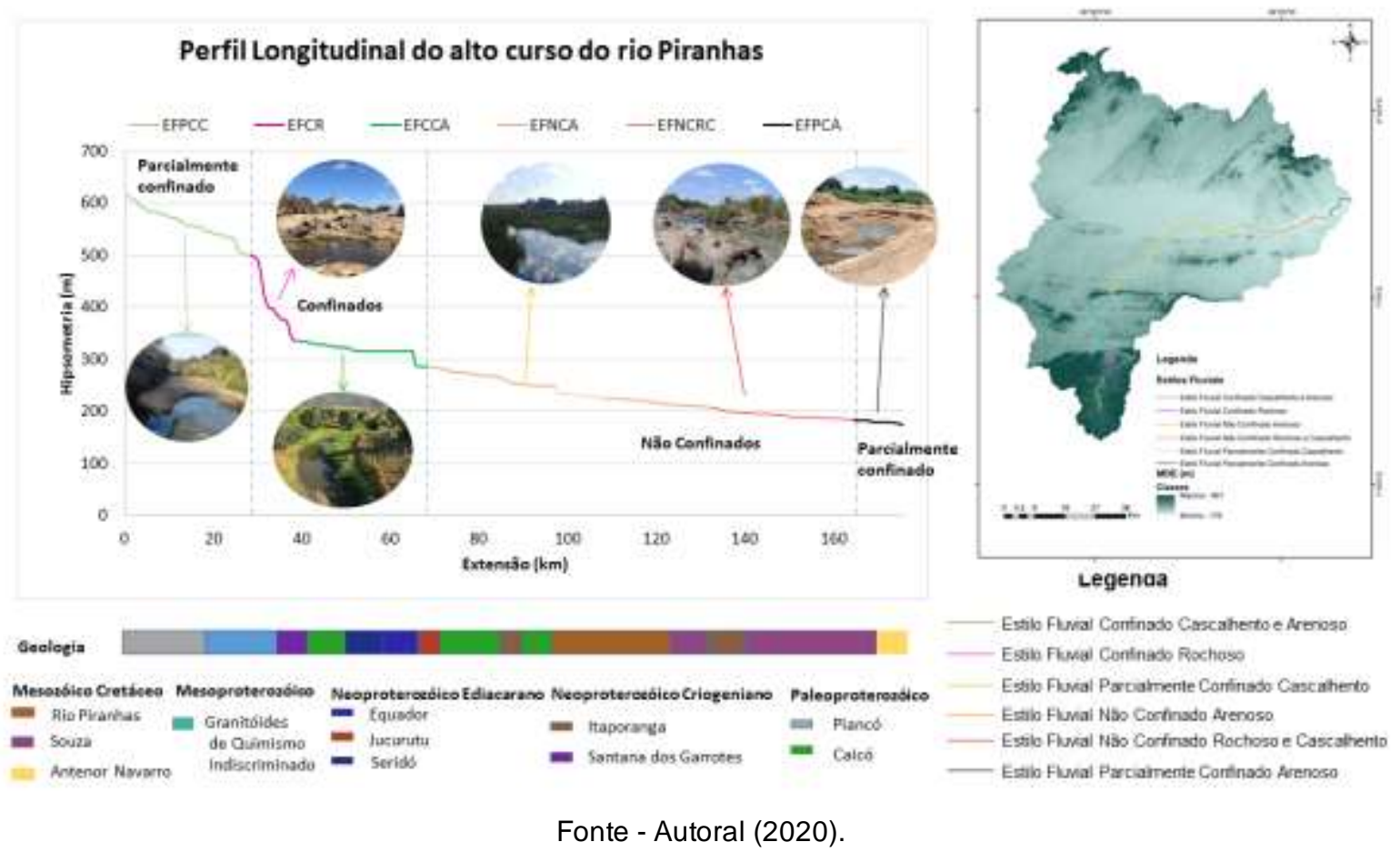

Uma variável importante na forma do perfil longitudinal é a geologia, que no caso do rio Piranhas, apresenta forma côncava, no entanto, com topo convexo e redução gradativa da declividade conforme vai se distanciando das áreas de cabeceira, onde a única ruptura de declive acentuada encontra-se no contato entre as unidades geológicas Piancó e Granitóides de Quimismo Indiscriminado. Sendo assim, o rio Piranhas escoa cerca de $90 \mathrm{~km}$ sobre geologia cristalina até encontrar embasamento sedimentar pertencente à unidade geológica Rio Piranhas (sedimentar).

Após a definição dos estilos fluviais, foi construída uma matriz de informações gerais dos estilos representados de acordo com sua configuração de vale, partindo dos confinados para os parcialmente confinados e, por fim, os não confinados, o que permitiu descrever os atributos distintivos entre eles (Figura 7). A nomenclatura dos estilos foi definida com base em sua morfologia e processos atuantes, ou seja, a característica e comportamento de cada alcance. De modo geral, o limite entre um estilo e outro foi definido através de alterações nas unidades geomórficas ex istentes
Caminhos de Geografia
Uberlândia-MG
v. 22, n. 82
ago./2021
p. 292-313
Página 301 
no ambiente fluvial, atributo chave na definição de estilos fluviais. Em última instância, o atributo selecionado para distinguir os estilos foi a textura de material de leito.

Figura 7 - Matriz de estilos fluviais do alto curso do rio Piranhas. EFCCA: Estilo fluvial Parcialmente Confinado Arenoso; EFCR: Estilo Fluvial Confinado Rochoso; EFPCC: Estilo Fluvial Parcialmente Confinado Cascalhento; EFPCA: Estilo Fluvial Parcialmente Confinado Arenoso; EFNCA - Estilo Fluvial Não Confinado Arenoso; Estilo Fluvial Não Confinado Rochoso e Cascalhento.

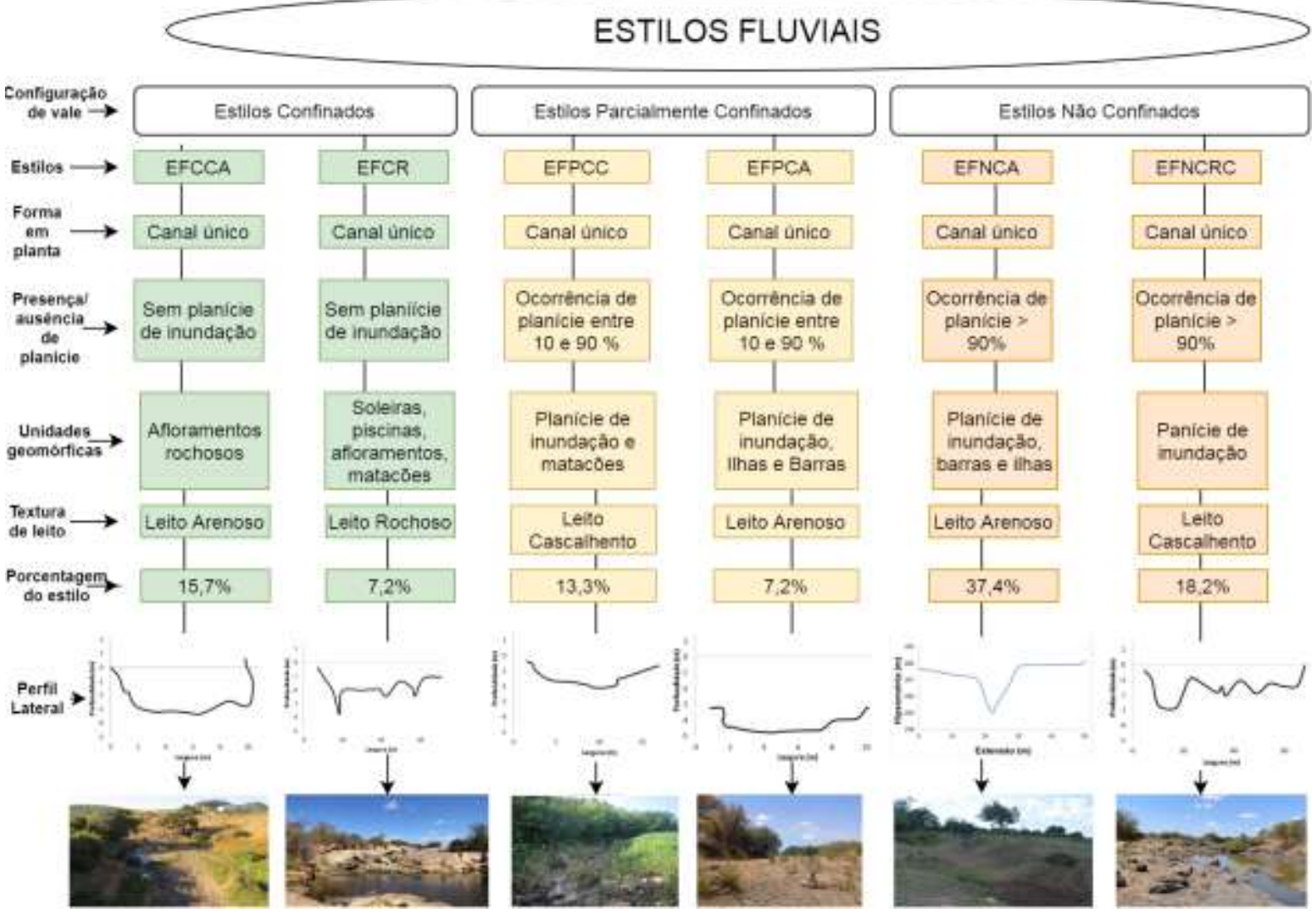

Fonte - Autoral (2020).

A bacia hidrográfica do alto curso do rio Piranhas possui apenas dois estilos fluviais confinados. Estes correspondem aos trechos que escoam sobre o cristalino das cabeceiras de drenagem. Nessa perspectiva são canais que não apresentam planícies de inundação nas margens fluviais e sofrem influência de suítes intrusivas e complexos metamórficos. O Estilo Fluvial Confinado Rochoso (EFCR) está situado onde ocorre uma ruptura de declive de $183 \mathrm{~m}$ de amplitude numa faixa de $13,5 \mathrm{~km}$ de extensão no rio Piranhas. Esta inclinação de superfície no sistema fluvial do EFCR condiciona uma morfologia de canal único com leito rochoso e assimétrico, e com a presença de unidades geomórficas como marmitas de abrasão, matacões e corredeiras sob um gradiente de 1,3\% (Figura 7). O Estilo Fluvial Confinado Cascalhento e Arenoso (EFCCA) está situado logo após o EFCR. Este estilo está situado inteiramente sobre um embasamento de complexos metamórficos. O que diferencia o EFCCA do EFCR é que existe uma diferença nos valores de gradiente entre esses estilos, pois o EFCCA possui gradiente de $0,8 \%$, além das unidades geomórficas distintas entre eles. Desta maneira, o EFCCA possui uma amplitude de $26 \mathrm{~m}$ em uma extensão de $29,5 \mathrm{~km}$, o que implica em uma declividade de $0,08 \%$. Com isso, esse estio é confinado na margem direita por controles litológicos e na margem esquerda por uma encosta. Também ocorrem maiores incidências de deposição de material sedimentar do tipo arenoso (Figura 8). A morfologia dos estilos fluviais respondem aos condicionantes fluviais em cada estilo, como é o caso do Estilo Fluvial Confinado Rochoso - EFCR situado em uma área cristalina com altas declividades, o que condiciona a exposição do leito rochoso, presença de matacões e corredeiras, como também, ausência de depósitos sedimentares de grãos finos como areia, silte e argila. Souza e Corrêa (2012) ao aplicarem

$\begin{array}{lllll}\text { Caminhos de Geografia } & \text { Uberlândia-MG } & \text { v. 22, n. } 82 & \text { ago./2021 } & \text { p. 292-313 Página } 302\end{array}$ 
a metodologia de estilos fluviais e caracterizar os trechos fluviais identificaram que as áreas íngremes com declividade entre $5 \%$ e $7 \%$ nas zonas de geologia cristalina abrigavam os estilos confinados dessa bacia. As áreas aplainadas correspondentes aos pedimentos dissecados com declividade média de 3\% nas zonas de planícies aluviais sobre áreas cristalinas abrigam os estilos parcialmente confinados, enquanto que as áreas aluviais majoritariamente planas abrigam os estilos não confinados. Isso se repete na bacia do alto curso do rio Piranhas, com exceção dos amplos plainos aluviais que não ocorrem no alto curso do rio Piranhas, mas unidades geológicas sedimentares.

Figura 8 - Estilos fluviais do alto curso do rio Piranhas.
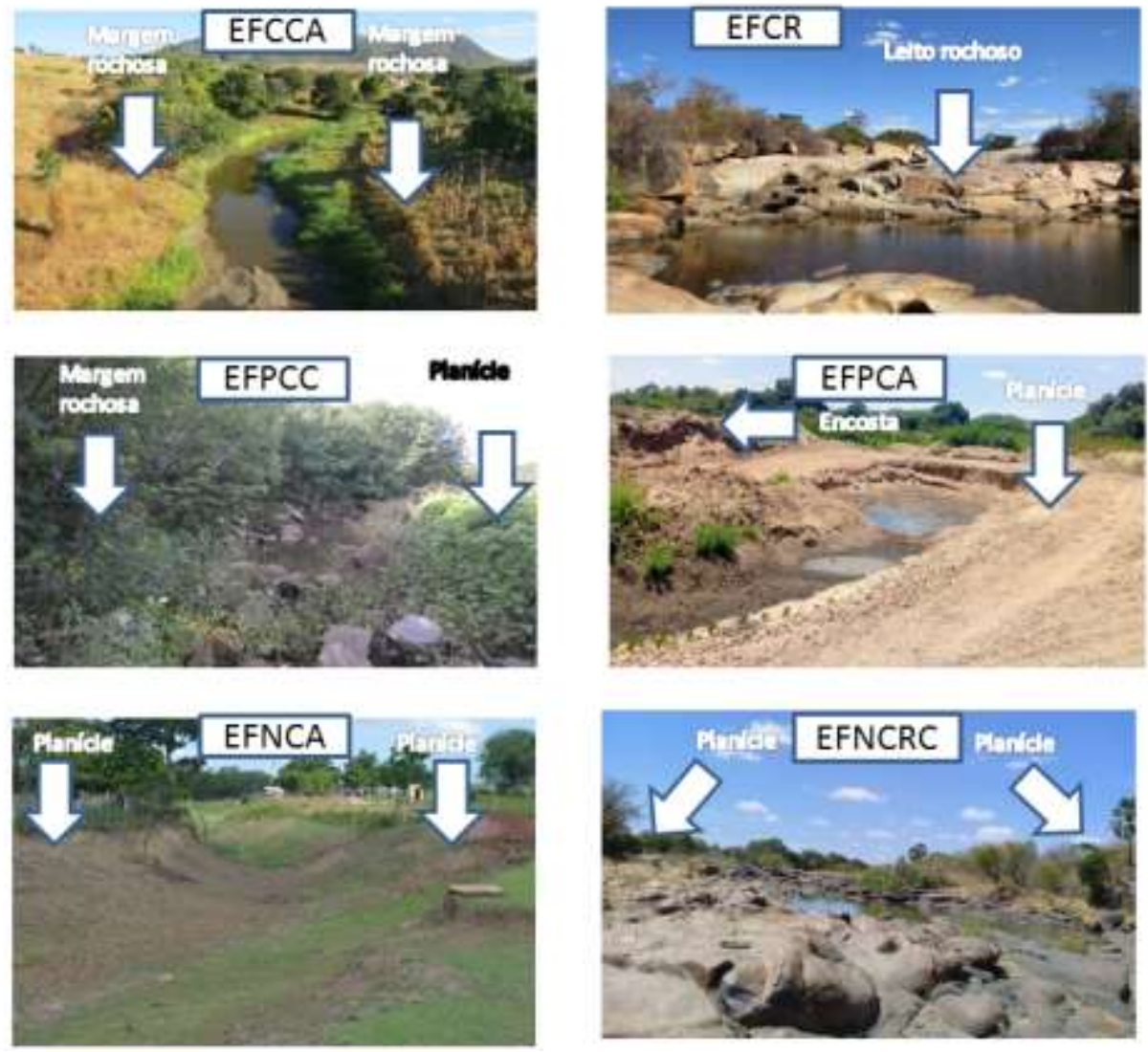

Fonte - Autoral (2020)

Ocorrem no alto rio Piranhas dois estilos fluviais parcialmente confinados. A característica singular entre eles são as planícies de inundação que ocorrem apenas em uma das margens. Por mais que haja alteração na disposição de inclinação da superfície de acordo com o trecho, os estilos fluviais parcialmente confinados do alto Piranhas apresentam baixos valores de declividade. Todavia, de acordo com Brierley e Fryirs (2005), a última instância para determinar um estilo de rio é o material de leito, e este foi o principal fator de diferenciação entre os estilos fluviais parcialmente confinados. $O$ Estilo Fluvial Parcialmente Confinado Cascalhento (EFPCC), apresenta canal único, planície de inundação contínua em uma das margens e a presença de matacões no ambiente fluvial, com a predominância de leito cascalhento (Figura 8). Desta maneira, por mais que esteja situado em uma área majoritariamente aplainada, a dissecação intensa das áreas de cabeceira oferta material sedimentar para o leito fluvial, que consegue transportar os finos na estação chuvosa e deixar predominando no ambiente fluvial o material cascalhento. O Estilo Fluvial Parcialmente Confinado Arenoso (EFPCA) está localizado na foz alto curso do rio do Piranhas. Este estilo fluvial apresenta canal único, com planícies de inundação, barras e ilhas. Nessa perspectiva, o fator confinante de uma das margens é a encosta fluvial que impede o extravasamento do fluxo na margem direita. É importante salientar que o canal é composto por um leito arenoso (Figura 8).

$\begin{array}{llllll}\text { Caminhos de Geografia } & \text { Uberlândia-MG } & \text { v. 22, n. } 82 & \text { ago./2021 } & \text { p. 292-313 } & \text { Página } 303\end{array}$


Segundo Brierley e Fryirs (2005), podem ser denominados como canais fluviais não confinados àqueles que apresentarem planície de inundação em mais de $90 \%$ em ambas as margens do trecho fluvial. Desta maneira, o fluxo tem probabilidade de extravasamento nos períodos de cheia, por não ter confinamento nas margens. O Estilo Fluvial Não Confinado Arenoso (EFNCA) é o trecho de maior extensão da bacia hidrográfica do alto curso do rio Piranhas, ocupando uma extensão de $37,4 \%$. Esse estilo fluvial não possui confinamento nas margens e apresenta planícies de inundação contínuas. Escoa sobre rochas cristalinas do paleoproterozóico e seus canais são largos, com valores que chegam em média a 53,7 m de largura e 2,98 m de profundidade. De modo geral, a largura está intimamente relacionada às áreas deposicionais correspondentes às planícies de inundação, enquanto na área de talvegue, observa-se um canal estreito em forma de "V" (Figura 8). O Estilo Fluvial Não Confinado Rochoso e Cascalhento (EFNCRC) está situado logo após o EFNCA. O que diferencia esses dois estilos fluviais é a disposição da textura predominante no leito, onde o EFNCRC apresenta a predominância de cascalhos e afloramentos rochosos no ambiente fluvial. Isto se explica a partir do entendimento que há uma variação de energia de fluxo entre esses estilos não confinados (Figura 9).

Dado o exposto, os estilos fluviais da bacia do alto curso do rio Piranhas apresentam variabilidade aparente na morfologia e no comportamento, tendo em vista que a morfologia dos sistemas fluviais está intimamente ligada aos processos atuantes. Nessa perspectiva, Wilson e Lorang (2000), af irmam que o SPI (Stream Power Index) é um indicativo de processo geomorfológico atuante em uma determinada área de captação, na medida em que a mensuração de erosão a partir da energia de fluxo da água em uma bacia está associada a um perfil longitudinal convexo e de deposição onde o perfil apresenta-se côncavo. O rio Piranhas apresenta os maiores índices de Stream Power nos locais onde ocorrem as maiores inclinações na superfície, e esses locais estão próximos à cabeceira de drenagem de substrato cristalino composto por rochas intrusivas plutônicas (Figura 9).

Figura 9 - Relação entre estilos fluviais e energia de fluxo do alto curso do rio Piranhas.

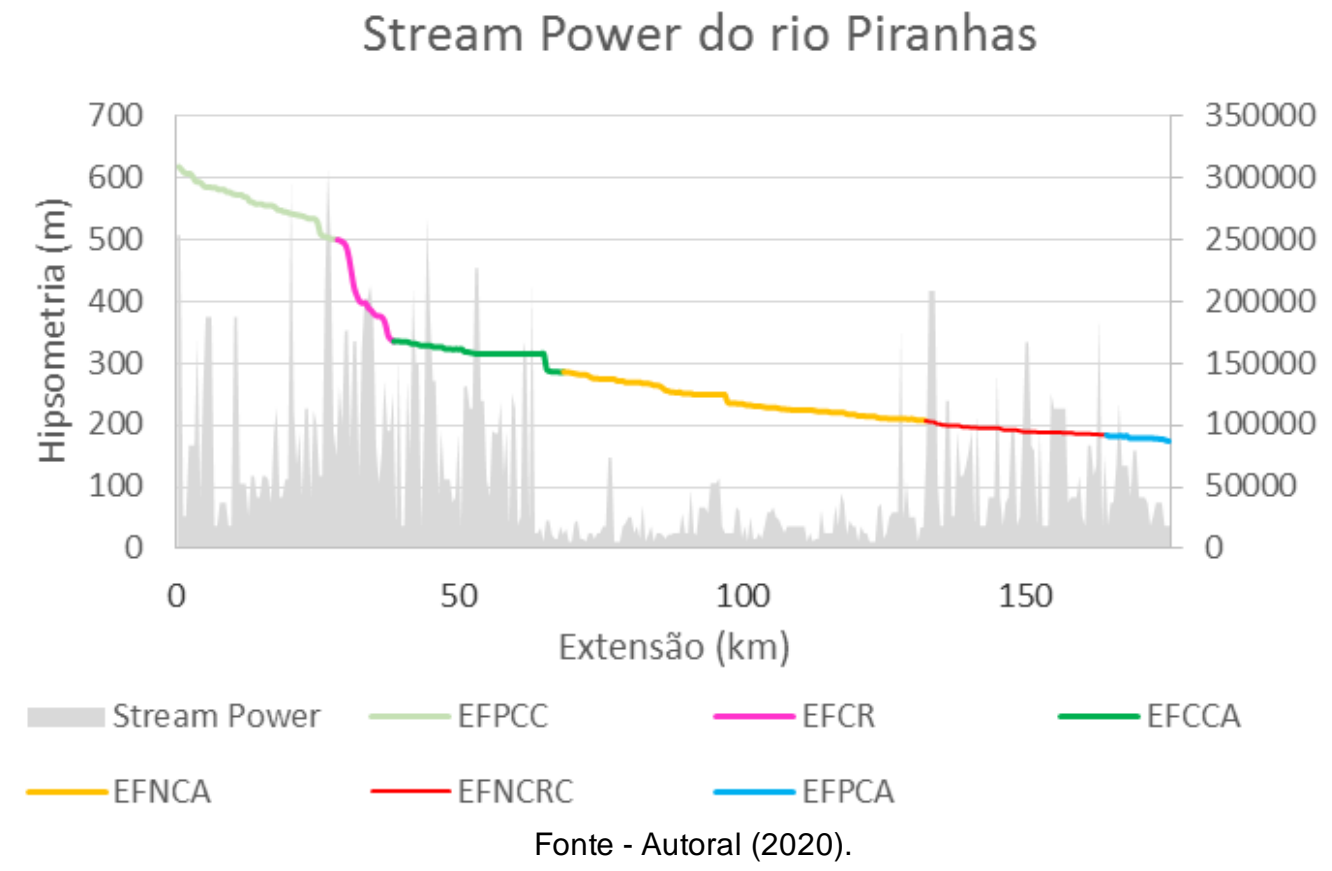

Observa-se na figura 8 que todo o trecho do EFNCA apresenta baixos valores de energia de fluxo, e isso ocorre por conta do controle da descarga fluvial feito pelo açude engenheiro ávidos, que pereniza artificialmente esse trecho do rio Piranhas visando o abastecimento e práticas de irrigação nesse trecho (SILVA; VIEIRA, 2017). O canal volta a apresentar picos de energia após a confluência com seu principal rio tributário (rio do Peixe) que ocorre no início do EFNCRC.

O Estilo Fluvial Parcialmente Confinado Cascalhento (EFPCC) está localizado na cabeceira do rio Piranhas e apresenta moderados índices de SPI. No EFCR e no EFCCA (confinados) ocorrem os

$\begin{array}{lllll}\text { Caminhos de Geografia } & \text { Uberlândia-MG } & \text { v. 22, n. } 82 & \text { ago./2021 } & \text { p. 292-313 Página } 304\end{array}$


primeiros picos seguidos de energia de fluxo da bacia hidrográfica do alto curso do rio Piranhas, onde delimitam o processo erosivo e característica confinante desses estilos. Nessa perspectiva, mesmo os índices de energia de fluxo variando de moderados a altos para essas áreas de cabeceira, as superfícies anômalas atuam como condicionantes de energia para o fluxo dos canais, o que gera processos de erosão e transporte (Tabela 1). Essas superfícies anômalas estão associadas a amplas variações litológicas correspondentes ao contato entre a Zona Transversal e o Domínio Rio Grande do Norte (Subprovíncias da Província Borborema) marcado pelo lineamento de Patos, que apresentam litotipos variados que condicionam as variações altimétricas e inclinações superficiais, conforme apresentado em Rodrigues (2020a). Fonstad (2003) ao estudar diversas estimativas de energia de fluxo em uma bacia de alta montanha no Novo México, conseguiu identificar que as variações de potência/energia de fluxo variavam de acordo com as características geológicas de diversos compartimentos/unidades geológicas da bacia. Da mesma maneira, ocorre com o alto curso do rio Piranhas, que varia sua energia de fluxo de acordo com as diversas variações geológicas que correspondem ao substrato dabacia.

Tabela 1 - Geoindicadores analisados para determinar os graus de liberdade de ajuste dos estilos fluviais do alto curso do rio Piranhas.

\begin{tabular}{|c|c|c|c|c|c|c|}
\hline \multicolumn{7}{|c|}{ MATRIZ DE SENSITIVIDADE DOS ESTILOS FLUVIAIS } \\
\hline & \multicolumn{6}{|c|}{ Estilos Fluviais } \\
\hline $\begin{array}{l}\text { Grau de } \\
\text { Liberdade }\end{array}$ & EFPCC & EFCR & EFCCA & EFNCA & EFNCRC & EFPCA \\
\hline \multicolumn{7}{|c|}{ ATRIBUTOS DE CANAL } \\
\hline Tamanho & $\begin{array}{l}9,8 \mathrm{~m} \text { de } \\
\text { largura e } \\
2,7 \mathrm{~m} \text { de } \\
\text { profundidade }\end{array}$ & $\begin{array}{l}29,9 \mathrm{~m} \text { de } \\
\text { largura e } \\
3,3 \mathrm{~m} \text { de } \\
\text { profundidade }\end{array}$ & $\begin{array}{l}9,8 \mathrm{~m} \text { de } \\
\text { largura e } \\
2,7 \mathrm{~m} \text { de } \\
\text { profundidad } \\
\mathrm{e}\end{array}$ & $\begin{array}{l}53,7 \mathrm{~m} \text { de } \\
\text { largura e } \\
2,9 \mathrm{~m} \text { de } \\
\text { profundidad } \\
\mathrm{e}\end{array}$ & $\begin{array}{l}33,7 \mathrm{~m} \text { de } \\
\text { largura e } \\
3,7 \mathrm{~m} \text { de } \\
\text { profundida } \\
\text { de }\end{array}$ & $\begin{array}{l}8,5 \mathrm{~m} \text { de } \\
\text { largura e } \\
1,5 \mathrm{~m} \text { de } \\
\text { profundidad } \\
\mathrm{e}\end{array}$ \\
\hline $\begin{array}{l}\text { Forma e } \\
\text { morfologia } \\
\text { da margem }\end{array}$ & $\begin{array}{l}\text { Margens } \\
\text { simétricas e } \\
\text { leito irregular }\end{array}$ & $\begin{array}{l}\text { Margens } \\
\text { assimétricas } \\
\text { e leito } \\
\text { irregular }\end{array}$ & $\begin{array}{l}\text { Margens } \\
\text { simétricas e } \\
\text { leito } \\
\text { irregular }\end{array}$ & $\begin{array}{l}\text { Margens } \\
\text { simétricas } \\
\text { e leito } \\
\text { regular }\end{array}$ & $\begin{array}{l}\text { Margens } \\
\text { assimétrica } \\
\text { s e leito } \\
\text { irregular }\end{array}$ & $\begin{array}{l}\text { Margem } \\
\text { simétrica e } \\
\text { leito } \\
\text { irregular }\end{array}$ \\
\hline \multicolumn{7}{|c|}{ FORMA EM PLANTA DO CANAL } \\
\hline $\begin{array}{l}\text { Número de } \\
\text { canais }\end{array}$ & Canal único & Canal único & Canal único & Canal único & $\begin{array}{l}\text { Canal } \\
\text { único }\end{array}$ & Canal único \\
\hline $\begin{array}{l}\text { Sinuosidade } \\
\text { de canais }\end{array}$ & Sinuoso & Retilíneo & Sinuoso & Sinuoso & Sinuoso & Sinuoso \\
\hline $\begin{array}{l}\text { Unidades } \\
\text { Geomórficas }\end{array}$ & $\begin{array}{l}\text { Terraço } \\
\text { fluviale } \\
\text { afloramentos } \\
\text { rochosos }\end{array}$ & $\begin{array}{l}\text { Matacões, } \\
\text { marmitas, } \\
\text { soleiras e } \\
\text { corredeiras }\end{array}$ & $\begin{array}{l}\text { Terraço } \\
\text { fluviale } \\
\text { afloramento } \\
\text { rochoso }\end{array}$ & $\begin{array}{l}\text { Planície de } \\
\text { inundação } \\
\text { contínua } \\
\text { nas duas } \\
\text { margens }\end{array}$ & $\begin{array}{l}\text { Planície de } \\
\text { inundação } \\
\text { e ilhas }\end{array}$ & $\begin{array}{l}\text { Planície de } \\
\text { inundação, } \\
\text { barras e } \\
\text { ilhase } \\
\text { terraço }\end{array}$ \\
\hline \multicolumn{7}{|c|}{ CARATERÍSTICA DO LEITO } \\
\hline $\begin{array}{l}\text { Textura do } \\
\text { leito }\end{array}$ & Cascalhento & Rochoso & $\begin{array}{l}\text { Cascalhent } \\
0\end{array}$ & Arenoso & $\begin{array}{l}\text { Cascalhent } \\
0\end{array}$ & Arenoso \\
\hline $\begin{array}{l}\text { Estabilidade } \\
\text { do leito }\end{array}$ & $\begin{array}{l}\text { Sem marcas } \\
\text { de incisão } \\
\text { vertical }\end{array}$ & $\begin{array}{l}\text { Sem marcas } \\
\text { de incisão } \\
\text { vertical }\end{array}$ & $\begin{array}{l}\text { Sem } \\
\text { marcas de } \\
\text { incisão } \\
\text { vertical }\end{array}$ & $\begin{array}{l}\text { Sem } \\
\text { marcas de } \\
\text { incisão } \\
\text { vertical }\end{array}$ & $\begin{array}{l}\text { Sem } \\
\text { marcas de } \\
\text { incisão } \\
\text { vertical }\end{array}$ & $\begin{array}{l}\text { Apresenta } \\
\text { marcas de } \\
\text { incisão } \\
\text { vertical }\end{array}$ \\
\hline \multicolumn{7}{|c|}{ ENERGIA E PROCESSO FLUVIAL } \\
\hline $\begin{array}{l}\text { Stream } \\
\text { Power Médio } \\
\left(w / m^{2}\right)\end{array}$ & 95116 & 131519 & 86550 & 20484 & 72688 & 45872 \\
\hline Processo & $\begin{array}{l}\text { Transporte e } \\
\text { Deposição }\end{array}$ & $\begin{array}{l}\text { Erosão e } \\
\text { transporte }\end{array}$ & Transporte & Deposição & Transporte & $\begin{array}{c}\text { Transporte } \\
\text { e } \\
\text { Deposição }\end{array}$ \\
\hline \multicolumn{7}{|c|}{ Fonte - Autoral (2020). } \\
\hline
\end{tabular}


É importante salientar que mesmo ocorrendo um pico de energia de fluxo no início do Estilo Fluvial Não Confinado Arenoso (EFNCA), o comportamento desse estilo é deposicional, ocorrendo uma queda nos índices de energia de fluxo desse estilo pelo fato de a superfície tornar-se aplainada na maior parte do trecho e ter vazão controlada artificialmente pelo açude Engenheiro Ávidos, conforme visto em Silva e Vieira (2017). O input de vazão advindo do rio do Peixe (principal afluente do rio Piranhas) condiciona o comportamento do rio Piranhas a apresentar característica de Estilo Fluvial Não Confiando Rochoso e Cascalhento (EFPCRC) com processo de transporte e remoção da maior parte do material arenoso. O ganho gradativo de energia de fluxo próximo à foz do rio Piranhas condiciona o aparecimento de outro estilo fluvial, o Estilo Fluvial Parcialmente Confinado Arenoso (EFPCA), que consegue apresentar planície de inundação em apenas uma das margens, e concentra material arenoso em excesso no leito (Tabela 1).

A partir da identificação e entendimento do comportamento de cada estilo fluvial, é possível partir para identificação dos níveis de sensitividade fluvial. Desta maneira, três geoindicadores foram avaliados para determinar a capacidade de ajuste dos estilos fluviais do alto Piranhas, que são: caraterística do leito, caraterística do canal, e a forma em planta do canal (Tabela 1). Foram analisados individualmente cada geoindicador no intuito de tabular os dados e organizá-los.

Desta maneira, foi possível gerar o resultado de sensitividade natural dos estilos fluviais de acordo com a proposta qualitativa proposta por Brierley e Friyrs (2005). A análise de sensitividade de estilos é uma análise simplificada onde os geoindicadores facilitam a identificação de áreas propensas à modificação numa perspectiva qualitativa (Quadro 2). O Quadro 2 indica que há diferenças entre a sensitividade dos estilos fluviais existentes no alto curso do rio Piranhas. Os rios que tem uma capacidade significativa de ajuste podem modificar seus leitos, morfologia e forma em planta (graus de liberdade). São sistemas que conseguem responder com facilidade a eventos de distúrbio e podem ser resilientes.

Quadro 2- Capacidade de ajuste dos estilos fluviais do alto curso do rio Piranhas.

\begin{tabular}{|c|c|c|c|c|c|c|}
\hline \multirow{2}{*}{$\begin{array}{l}\text { Estilo } \\
\text { Fluvial }\end{array}$} & \multirow{2}{*}{$\begin{array}{l}\text { Distribuição na } \\
\text { bacia }\end{array}$} & \multicolumn{4}{|c|}{ Capacidade de ajuste } & \multirow{2}{*}{ Principais ajustes } \\
\hline & & $\begin{array}{c}\text { Morfologia } \\
\text { do canal }\end{array}$ & $\begin{array}{c}\text { Forma em } \\
\text { planta }\end{array}$ & \begin{tabular}{|c|}
$\begin{array}{c}\text { Característica } \\
\text { do leito }\end{array}$ \\
\end{tabular} & Sensitividade & \\
\hline EFPCC & $13,30 \%$ & & & & Moderada & $\begin{array}{c}\text { Retrabalhamento da planície de inundação e remoção do } \\
\text { material fino durante os eventos de alta magnitude. }\end{array}$ \\
\hline EFCR & $7,20 \%$ & & & & Baixa & Sem ajustes \\
\hline EFCCA & $15,70 \%$ & & & & Baixa & Sem ajustes \\
\hline EFNCA & $37,40 \%$ & & & & Moderada & $\begin{array}{c}\text { Poucos ajustes no que tange à forma em planta e } \\
\text { sinuosidade, tendo em vista o controle da vazão pelo } \\
\text { açude eng. Ávidos compromete a competência energética } \\
\text { do sistema fluvial. } \\
\end{array}$ \\
\hline EFNCRC & $18,20 \%$ & & & & Alta & $\begin{array}{c}\text { Ajuste na largura e número de canais, considerando o } \\
\text { potencial energético do sistema fluvial e a baixa } \\
\text { resistência das margens majoritariamente arenosas. }\end{array}$ \\
\hline EFPCA & $7,20 \%$ & & & & Moderada & $\begin{array}{l}\text { Ajustes localizados na largura e sinuosidade do trecho, } \\
\text { considerando as margens arenosas de baixa resistência. }\end{array}$ \\
\hline
\end{tabular}

\begin{tabular}{|l|}
\hline \multicolumn{1}{|c|}{ Legenda } \\
\hline Capacidade de ajuste baixa \\
\hline Capacidade de ajuste moderada \\
\hline Capacidade de ajuste alta \\
\hline
\end{tabular}

Fonte - Autoral (2020).

Os canais com baixa capacidade de ajuste não apresentam respostas significativas a eventos de distúrbio. Eles não apresentam propensão para ajuste lateral nem vertical (BRIERLEY e FRIYRS, 2005). Nesse sentido, os estilos fluviais confinados apresentam baixa capacidade de ajuste, ou seja, baixa sensitividade à mudança e não são canais resilientes. Estas características são geradas pelos controles litológicos que existem nestes estilos, que funcionam como elementos de resistência na paisagem fluvial.

Os canais parcialmente confinados geralmente são controlados por mat eriais rochosos em uma das margens ou materiais com alta coesão. Os ajustes laterais são restritos a áreas de acumulação em

$\begin{array}{lllll}\text { Caminhos de Geografia } & \text { Uberlândia-MG } & \text { v. 22, n. } 82 & \text { ago./2021 } & \text { p. 292-313 Página } 306\end{array}$


uma das margens como ocorrem com as planícies de inundação descontínuas (BRIERLEY e FRIYRS, 2005). Nesse sentido, os estilos parcialmente confinados da bacia apresentam capacidade de ajuste moderada, e apenas os eventos de alta magnitude são capazes de gerar modificações na paisagem fluvial destes estilos.

O Estilo Fluvial Não Confinado Arenoso (EFNCA) ocorre em áreas de baixa energia, o que faz com que haja poucos ajustes no ambiente fluvial, ou seja, a sensitividade apresenta potencial moderado, tendo em vista que por mais que ocorra a presença de unidades geomórficas de baixa coesão compostas por textura arenosa, a baixa energia não consegue retrabalhar estas unidades. $O$ Estilo Fluvial Não Confinado Rochoso e Cascalhento (EFNCRC) é o único trecho que apresenta o índice de sensitividade alto. Isso ocorre porque a largura do canal pode ser ajustada lateralmente, tendo em vista que as taxas de energia condicionam os processos de erosão nas margens. Além disso, a resistência baixa das margens permite ajustes no número e sinuosidade de canais.

De maneira geral, a análise da variação da sensitividade foi utilizada para verificar a variação no ajustamento dos estilos entre os anos de 2004 e 2009, sendo procedimento fundamental para geração de dados quantitativos sobre modificações no ambiente fluvial, conforme observado na Figura 10. Após da identificação no ajustamento dos estilos fluviais de acordo com o índice de sinuosidade apresentado entre o período de tempo analisado, esses dados foram tratados com base na estatística descritiva (média, mediana, amplitude, máximo e mínimo).

Figura 10 - Índice de sinuosidade dos estilos parcialmente confinados e não confinados entre 2004 e 2019.
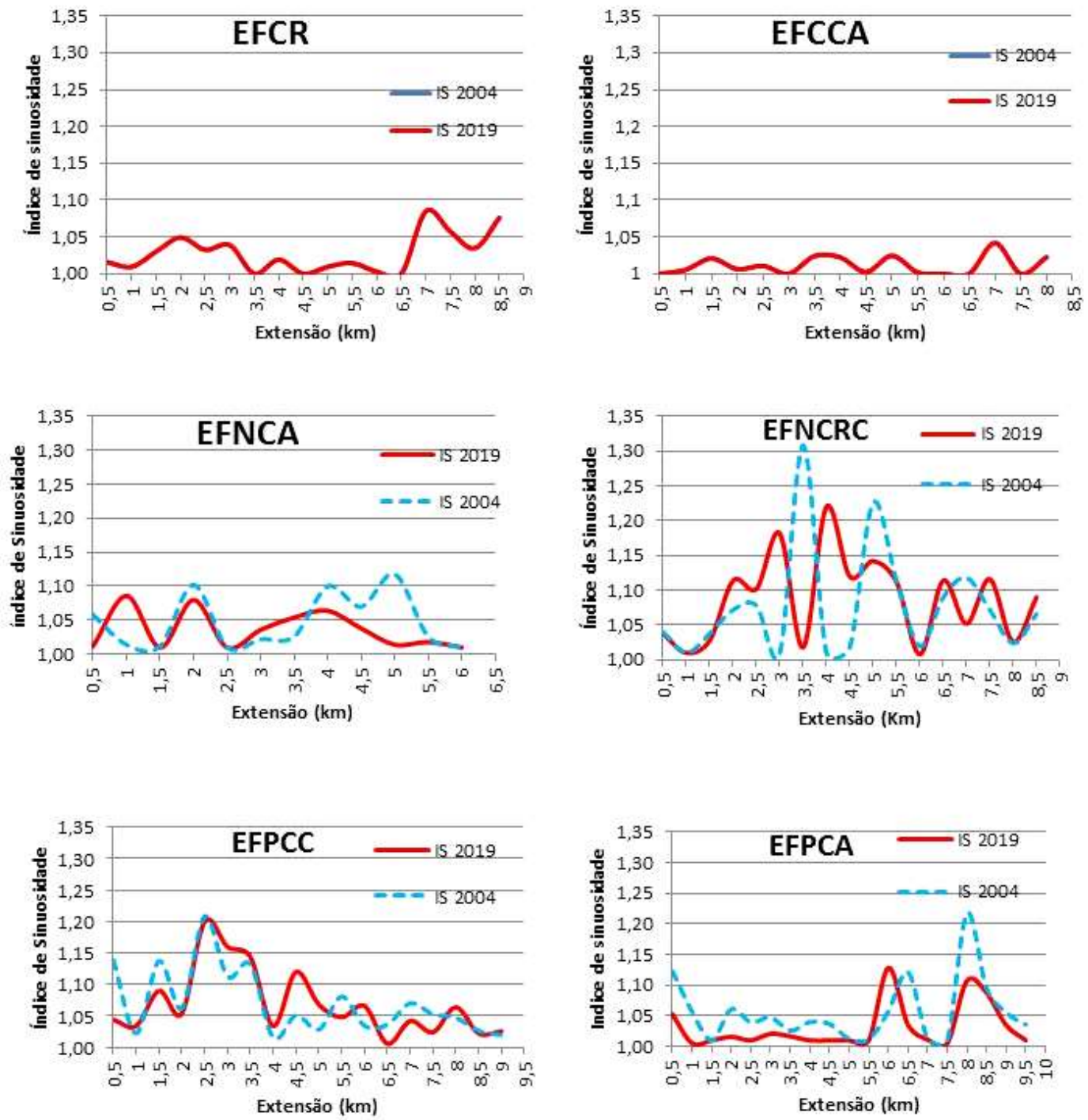

Fonte - Autoral (2020). 
A figura 10 indica que não houve variação de sinuosidade nos estilos fluviais confinados, considerando seus baixos níveis de sensitividade. De modo contrário, ocorre variação na sinuos idade entre 2004 e 2019 em todos os estilos que apresentaram índices de sensitividade moderados e altos. É importante salientar que a variabilidade entre os índices de sensitividade aponta mudanças no que tange à curvatura dos canais. Observa-se de maneira geral, que os estilos fluviais apresentavam maior sinuosidade no ano de 2004, e que para o ano de 2019 indica uma diminuição na sinuosidade dos estilos. Langat et al. (2020) ao aplicar o índice de sinuosidade para identificar as migrações laterais e ajustes geomórficos no rio Tana - Kênia, percebeu que os trechos que apresentam ajustes fluviais estão associados a áreas de baixa resistência, seja pela retirada da vegetação, pela alteração do uso da terra ou até mesmo alterações nos níveis de energia e controle artificial da drenagem. No alto curso do rio Piranhas os estilos fluviais com maior propensão à mudança são os que apresentam baixa resistência, implicando em maiores ajustes na forma em planta desses canais.

O aumento e regressão do índice de sinuosidade demonstra que os estilos fluviais com propensão à modificação apresentam em alguns trechos alta variação de sinuosidade, possibilitando inferir que estes estilos apresentam boa capacidade de ajuste, como é o caso do Estilo Fluvial não Confinado Rochoso e Cascalhento (EFNCRC), Estilo Fluvial Não Confiando Arenoso (EFNCA), Estilo Fluvial Parcialmente Confinado Cascalhento (EFPCC) e Estilo Fluvial Parcialmente Confinado Arenoso (EFPCA). Como este trabalho não trata especificamente sobre as forçar de distúrbio que podem ser antrópicas ou naturais, ocorre a limitação de tratar especificamente sobre os dados de modificação da forma em planta dos estilos fluviais propensos à modificação. Para ter um melhor entendimento acerca da discussão sobre o índice de sinuosidade, os dados foram analisados a partir de boxplots (Figura 11).

Figura 11 - Boxplot representando os dados dos índices de sinuosidade para os anos de 2004 e 2019 dos estilos fluviais com moderada e alta sensitividade.
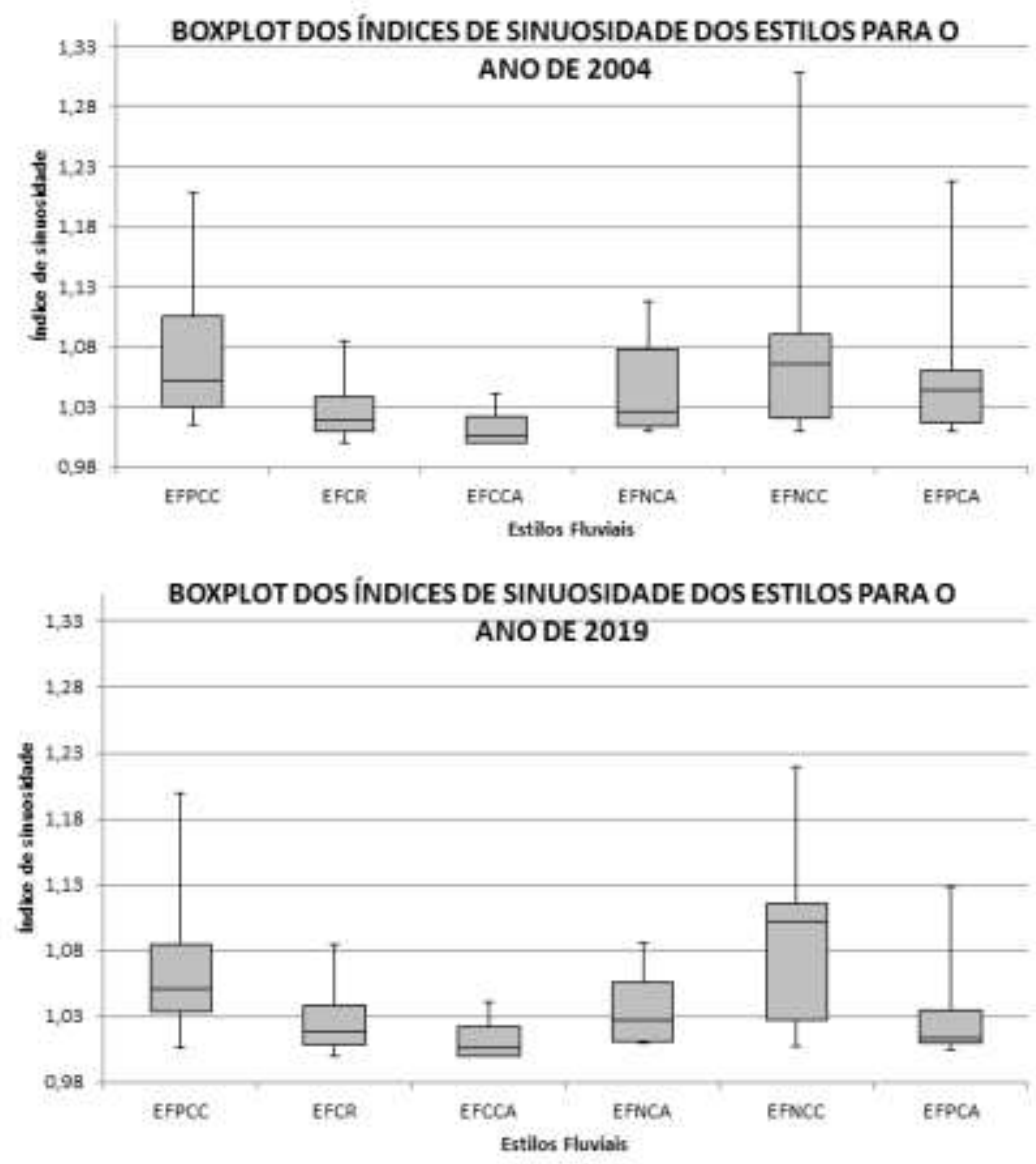

Fonte - Autoral (2020). 
De acordo com os dados representados nos boxplots (Figura 11), os estilos fluviais confinados não apresentaram ajustes na sinuosidade entre o ano de 2004 e 2019. Pode-se observar que dentre os estilos que apresentaram maior propensão à mudança, ou seja, os maio res índices de sensitividade (Quadro 2), o EFPCA é o estilo que apresenta menor variabilidade de sinuosidade no trecho analisado considerando o $1^{\circ}$ e $3^{\circ}$ quartis que indicam a maioria dos dados sobre o índice de sinuosidade desse estilo, variando a sinuosidade máxima de 1,22 em 2004 para 1,13 em 2019 e sinuosidade mínima inalterada de 1,01 entre o período de tempo analisado. A mediana de 1,04 em 2004 e de 1,01 em 2019 indica que o canal era mais sinuoso e passou a ser mais retilíneo.

O EFPCC apresenta em 2019 uma redução de sinuosidade no terceiro quartil do trecho analisado, onde ocorre uma redução da sinuosidade dos trechos mais tortuosos de 2004. Nessa perspectiva, os valores máximos de sinuosidade mantiveram-se inalterados sob um índice de sinuosidade de 1,21. Os valores mínimos de sinuosidade também se mantiveram inalterados nesse trecho do EFPCC, sob o índice de 1,02. A real mudança ocorreu com alguns trechos que correspondiam ao $3^{\circ}$ quartil em 2004 sob um índice de sinuosidade de 1,10 e que passaram a ser de 1,08. De maneira geral, os estilos fluviais parcialmente confinados apresentaram propensão à mudança em faixas localizadas onde ocorrem a presença de planícies de inundação, inibindo alterações dramáticas na forma em planta dos sistemas fluviais, conforme apontado pelos geoindicadores de sensitividade no Quadro 2. Brierley e Friyrs (2005) afirmam que os estilos fluviais parcialmente confinados ficam restritos a apresentar mudanças apenas nas áreas que apresentam processos de acreção de material sedimentar, os quais geram as planícies de inundação, que no caso desta pesquisa, as planícies apresentam-se descontínuas nos estilos parcialmente confinados.

Diferentemente do que ocorreram com os estilos confinados e parcialmente confinados, os estilos não confinados apresentaram maior variabilidade no índice de sinuosidade dos trechos analisados. Desta maneira, o EFNCA apresenta em 2004 o máximo do índice de sinuosidade de 1,12 que passa a ser de 1,09 em 2019. O valor mínimo e a mediana se mantiveram invariáveis, com o valor de 1,01 e 1,03 respectivamente. As maiores mudanças ocorreram no $3^{\circ}$ quartil, que apresentou redução de 0,2 na amplitude de sinuosidade desse indicativo entre 2004 e 2019, apontando para uma baixa retilinização na maioria dos pontos anteriormente sinuosos.

O EFNCRC apresentou aumento no índice de sinuosidade entre os anos de 2004 e 2019, tendo em vista que este estilo foi o único da bacia que apresentou alta sensitividade entre todos os estilos identificados (Quadro 2), principalmente no $3^{\circ}$ quartil entre 2004 e 2019, que passou a ter valores de 1,09 para 1,12 respectivamente. Os valores máximos também apresentaram mudanças significativas de sinuosidade, que passaram de 1,31 para 1,22 entre 2004 e 2019 respectivamente, evidenciando uma redução nos valores máximos. Os valores mínimos de sinuosidade mantiveram-se invariáveis apresentando 1,01 e a mediana indicou que houve aumento de sinuosidade mediana, que passou de 1,07 para 1,10 entre 2004 e 2019 respectivamente. Nessa perspectiva, o EFNCRC é o que apresentou a maior variação nos índices de sinuosidade do trecho analisado e consequentemente, maior modificação na forma em planta do canal.

Nessa perspectiva, o índice de sensitividade e a análise dos dados de sinuosidade permitiram identificar o estilo fluvial com maior probabilidade à mudança na bacia do alto curso do rio Piranhas. Após a definição do estilo de rio que apresenta maior propensão à mudança na bacia, foi observada a forma em planta do EFNCRC a partir de imagens de satélite disponibilizadas pelo Google Earth para os anos de 2004 e 2019 (Figura 12).

$\begin{array}{llllll}\text { Caminhos de Geografia } & \text { Uberlândia-MG } & \text { v. 22, n. } 82 & \text { ago./2021 } & \text { p. 292-313 } & \text { Página } 309\end{array}$


Figura 12 - Trecho correspondente ao ponto de maior alteração morfológica identificada no Estilo Fluvial Não Confinado Rochoso e Cascalhento.
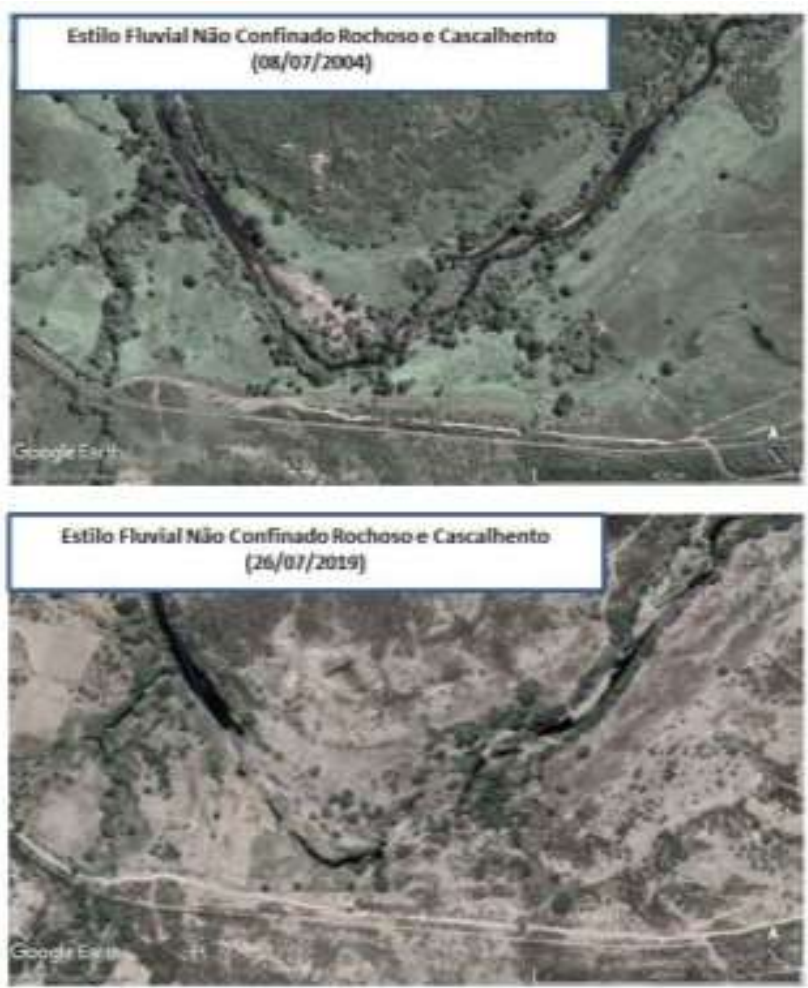

Fonte - Google Earth (2019).

A figura 12 demonstra que houve uma redução na sinuosidade nesse ponto do EFNCRC, onde ocorre um preenchimento de canal secundário e uma descontinuidade no talvegue desse estilo fluvial, indicando que as margens e o leito são móveis, propícios a modificações, dependendo do evento de perturbação que ocorrer na bacia. Desta maneira, por mais que o substrato seja rochoso, composto pelas rochas da unidade geológica Sousa (sedimentar), o leito é majoritariamente constituído de textura cascalhenta e acompanhados de uma pequena taxa de sedimentos arenosos que podem assorear o leito e migrar o talvegue conforme a dinâmica fluvial se altera.

Souza (2015) ao aplicar a metodologia de estilos fluviais na bacia do riacho do Saco em Pernambuco conseguiu identificar que os estilos fluviais que menos apresentaram potencial de modificação for am os estilos controlados por margens rochosas. Entretanto, o referido autor conseguiu identificar que os canais que apresentavam alta sensitividade eram canais compostos de leitos com elevadas taxas de material arenoso e energia suficiente para modificar a forma em planta do ambiente fluvial. De modo semelhante, o EFNCRC na bacia do alto curso do rio Piranhas apresenta elevadas taxas de material sedimentar do tipo cascalhento e energia suficiente para alterar as condições morfológicas da planta do canal. Todavia, as pesquisas com base em sensitividade de ambientes fluviais no semiárido brasileiro ainda são pioneiras nessa área do conhecimento, o que impossibilita momentaneamente 0 diálogo dos resultados desta pesquisa com outros trabalhos com a mesma temática no perímetro seco do Brasil.

\section{CONSIDERAÇÕES FINAIS}

O sistema fluvial semiárido brasileiro comumente vem sendo estudado através de adaptações de abordagens teórico metodológicas aplicadas em ambientes úmidos, o que na maio ria das vezes pode gerar informações e entendimentos equivocados acerca desse sistema geomorfológico. Dentro dessa perspectiva, achou-se necessário nesta pesquisa recorrer a um conceito que permitisse o entendimento da dinâmica de canais semiáridos na bacia do alto Piranhas, no semiárido paraibano.

$\begin{array}{lllll}\text { Caminhos de Geografia } & \text { Uberlândia-MG } & \text { v. 22, n. } 82 & \text { ago./2021 } & \text { p. 292-313 Página } 310\end{array}$


A proposta teórico metodológica de sensitividade acompanhada dos estilos fluviais, ambas de Brierley e Friyrs (2005) permitiu a aplicação sem adaptações para a bacia do alto Piranhas, e ass im foi possível definir os trechos fluviais com maior propensão morfológica à mudança, principalmente o Estilo Fluvial Não Confinado Rochoso e Cascalhento (EFNCRC) sob alta sensitividade, Estilo Fluvial Não Confinado Arenoso (EFNCA) sob sensitividade moderada, Estilo Fluvial Parcialmente Confinado Cascalhento (EFPCC) sob sensitividade moderada e Estilo Fluvial Parcialmente Confinado Arenoso (EFPCA) sob sensitividade moderada. Esses estilos apresentaram maior propensão à mudança pelo fato de seus geoindicadores e respectivos subgeoindicadores apresentaram baixa resistência frente aos eventos de alta magnitude, sendo esse último não abordado nessa pesquisa. O enf oque principal nesse momento de def inição da sensitividade tratou sobre os atributos de cada subgeoindicador, que ao serem as so ciados qualitativamente à proposta de sensitividade de Brierley e Friyrs, funcionaram como indicadores de probabilidade à mudança.

A aplicação do índice de sinuosidade e representação desses dados em gráficos boxplots foram fundamentais para confirmar as áreas com maior propensão à mudança, facilitando a explicação dos dados quantitativos. Com base na sensitividade dos estilos encontrados na bacia do rio Piranhas, observou-se que o EFNCRC, por mais que possua controle de evolução vertical por conta do substrato rochoso, apresentou alta propensão à mudança, tendo em vista as amplas planícies de inundação contínuas em ambas as margens e compostas de material sedimentar pouco coeso, permitindo alteração morfológica da forma em planta entre os anos de 2004 e 2019.

\section{AGRADECIMENTOS}

Agradecemos à Capes pelo financiamento da pesquisa no Brasil e oportunidade.

\section{REFERÊNCIAS}

BOAS, G.; MARÇAL, M. AVALIAÇÃO DA SENSITIVIDADE DO SISTEMA FLUVIAL NO ALTO-MÉDIO VALE DO RIO MACAÉ (RJ). Revista Brasileira de Geomorfologia, [S.L.], v. 14, n. 1, p. 93-102, 14 dez. 2013. https://doi.org/10.20502/rbg.v14i1.395

BRIERLEY, G.; FRYIRS, K. 2000. River styles, a Geomorphic Approach to Catchment Characterization: Implications for River Reabilitation in Bega Catchment, New South Wales, Australia. 2000. https://doi.org/10.1007/s002670010052

BRIERLEY, G.; FRYIRS, K. Geomorphology and River Management: applications of the river styles framework. Oxford: Blackwell Publishing, 2005. 412 p. https://doi.org/10.1002/9780470751367

BRUNSDEN, Denys. A critical assessment of the sensitivity concept in geomorphology. Catena, [s. L.], v. 42, n. 4, p.99-123, jan. 2001. https://doi.org/10.1016/S0341-8162(00)00134-X

DANIELSON, T. Utilizing a High Resolution Digital Elevation Model (DEM) to Apply Stream Power Index (SPI) to the Gilmore Creek Watershed in Winona County, Minnesota. Papers In Resource Analysis, Winona, v. 15, n. 11, p.1-11, nov. 2013.

DOMINGUES, R. Ordenamento territorial, governança e a transposição de águas do São Francisco: uma perspectiva. GOT, n.8, pp.51-74. 2015. https://doi.org/10.17127/got/2015.8.004

FERNANDEZ, O. A CLASSIFICAÇÃO FLUVIAL DE ROSGEN APLICADA EM CÓRREGOS DA REGIÃO OESTE DO ESTADO DO PARANÁ, BRASIL. Revista do Departamento de Geografia de São Paulo. 31, 1 - 13. 2016. https://doi.org/10.11606/rdg.v31i0.98837

FONSTAD, M. Spatial variation in the power of mountain streams in the Sangre de Cristo Mountains, New Mexico. Geomorphology, v.55, n.1. 2003. https://doi.org/10.1016/S0169-555X(03)00133-8

FRYIS, K. River Sensitivity: a lost foundation concept in fluvial geomorphology. Earth Surface Processes and Landforms, v. 42, n. 1. 55 - 70. 2017. https://doi.org/10.1002/esp.3940

FRIYRS, K. Guiding principles for assessing geomorphic river condition: application of a Framework in the Bega catchment, South Coast, New South Wales, Australia. Catena, v. 53, n. 1. 2003. https://doi.org/10.1016/S0341-8162(02)00199-6 
KLEINA, M.; SANTOS, L. SENSITIVIDADE FLUVIAL DA DRENAGEM PRINCIPAL DA BACIA HIDROGRÁFICA DO RIO SAGRADO -SERRA DO MAR PARANAENSE. Raega: O Espaço Geográfico em Análise, Curitiba, v. 41, n. 1, p. 174-188, ago. 2017. https://doi.org/10.5380/raega.v41i0.51903

KOUSKY, V. E.; GAN, M. A. Upper tropospheric cyclonic vortices in the tropical South Atlantic. Tellus, Copenhagen, n. 33, p.538-551, 1981. https://doi.org/10.3402/tellusa.v33i6.10775

LANGAT, P. et al. Characterisation of channel morphological pattern changes and flood corridor dynamics of the tropical Tana River fluvial systems, Kenya. Journal of African Earth Sciences. V, 163. S.N. S.I. 2020. https://doi.org/10.1016/j.jafrearsci.2019.103748

MAIA, R. P.; BEZERRA, H. R. NEOTECTÔNICA, GEOMORFOLOGIA E SISTEMAS FLUVIAIS: UMA ANÁLISE PRELIMINAR DO CONTEXTO NORDESTINO. Revista Brasileira de Geomorfologia, Uberlândia, v. 12, n. 3, p.37-46, 2010. https://doi.org/10.20502/rbg.v12i0.257

MAIA, R; SOUZA, J. ANÁLISE E CARACTERIZAÇÃO EM AMBIENTE SEMIÁRIDO DOS ESTILOS FLUVIAIS NA BACIA RIACHO JUCURUTU - PB. SINAGEO, Maringá, 2016.

NOGUEIRA, F; OLIVEIRA, M; CASTRO, D. Estudo Magnético e Gravimétrico do Arcabouço Estrutural da Bacia do Rio do Peixe - PB. Revista de Geologia, V. 17, N. 1. 2004.

REID, H. BRIERLEY, G. Assessing geomorphic sensitivity in relation to river capacity for adjustment. Geomorphology, v. 251, n. 15. 2015. https://doi.org/10.1016/j.geomorph.2015.09.009

RODRIGUES, J; SOUZA, J. Parâmetros de controle de estilos fluviais na bacia hidrográfica do alto curso do rio Piranhas, semiárido paraibano. Revista Caderno de Geografia, v. 30, n, 62. 2020a. https://doi.org/10.5752/P.2318-2962.2020v30n62p650

RODRIGUES, J. ESPACIALIZAÇÃO DAS CHUVAS EM UMA BACIA HIDROGRÁFICA NO SEMIÁRIDO PARAIBANO. Revista Regne, v. 6, n. 1. 2020b. https://doi.org/10.21680/24473359.2020v6n1ID18143

RODRIGUES, J; SOUZA, J. ESTILOS FLUVIAIS EM UMA BACIA DE DRENAGEM DO SEMIÁRIDO PARAIBANO- MUNICÍPIO DE SÃO JOÃO DO TIGRE (PB). SINAGEO, Maringá, v. S.v., ed. S.n., 2016.

ROSA, P; FREDDUZZI, A; CENCETTI, C. Stream Power Determination in GIS: An Index to Evaluate the Most 'Sensitive'Points of a River. Water, [s.I.], v. 11, n. 6, p.1145-1156, 31 maio 2019. https://doi.org/10.3390/w11061145

ROSGEN, D. A classification of natural rivers. EISEVIER. CATENA. 1994. https://doi.org/10.1016/0341-8162(94)90001-9

SILVA, A.; SOUZA, J. CARACTERIZAÇÃO HIDROSSEDIMENTOLÓGICA DOS TRECHOS ALUVIAIS DA BACIA RIACHO DO TIGRE - PB. Caminhos de Geografia, [S.L.], v. 18, n. 63, p. 5789, 29 set. 2017. https://doi.org/10.14393/RCG186303

SILVA, E; VIEIRA, A. Simulação integrada dos recursos hídricos nos reservatórios Engenheiro Ávidos e São Gonçalo na Paraíba. Revista Verde de Agroecologia e Desenvolvimento Sustentável, v. 12, n. 5. 2017. https://doi.org/10.18378/rvads.v12i5.5443

SOUZA, J. O. P.; ALMEIDA, J. Processos Fluviais em Terras Secas. Revista Okara, João Pessoa, v. 9, n. 1, p.108-122, 2015. https://doi.org/10.20502/rbg.v16i4.777

SOUZA, J. Modelos da Evolução da Dinâmica Fluvial em Ambiente Semiárido - Bacia do Riacho do Saco, Serra Talhada, Pernambuco. 2014. 191 f. Tese (Doutorado em Geografia) - Universidade Federal de Pernambuco, Pernambuco. 2014.

SOUZA, J. O. P. ANÁLISE DA SENSITIVIDADE DA PAISAGEM NA BACIA DO RIACHO DO SACO PE. Revista Brasileira de Geomorfologia, v. 16, n. 4. 2015.

SOUZA, J; BARROS, A; CORREA, A. Estilos fluviais num ambiente semiárido: bacia do Riacho do Saco, Pernambuco. Finisterra [online], n.102, pp.3-23. 2016. https://doi.org/10.18055/Finis3737

SOUZA, J. SISTEMA FLUVIAL E PLANEJAMENTO LOCAL NO SEMIÁRIDO. Mercator, v. 11, n.24. 2012. https://doi.org/10.4215/RM2012.1124.0010

$\begin{array}{llllll}\text { Caminhos de Geografia } & \text { Uberlândia-MG } & \text { v. 22, n. } 82 & \text { ago./2021 } & \text { p. 292-313 } & \text { Página 312 }\end{array}$


SUTFIN, N. A. Geomorphology. A geomorphic classification of ephemeral channels in a mountainous, arid region, southwestern Arizona, USA. Geomorphology, v.221, n. 15.2014. https://doi.org/10.1016/i.geomorph.2014.06.005

VAREJÃO-SILVA, M. A. METEOROLOGIA E CLIMATOLOGIA. 2. ed. Recife: Versão Digital, 2006. 463 p.VICENTE, L. E.; PEREZ FILHO, A. ABORDAGEM SISTÊMICA E GEOGRAFIA. Geografia, Rio Claro, v. 28, n. 3, p.323-344, dez. 2003.

Recebido em: 12/07/2020

Aceito para publicação em:06/04/2021 